\title{
LOAN PRODUCTION AND MONETARY POLICY
}

\author{
Miguel Casares \\ Luca Deidda \\ Jose E. Galdon-Sanchez
}

\section{WORKING PAPERS}

$2016 / 12$

(ब)

CUEC 


\title{
CEnTRO Ricerche ECONOMICHE NORd SUd ( CRENOS) \\ UNIVERSITÀ DI CAGLIARI \\ UNIVERSITÀ DI SASSARI
}

\begin{abstract}
CRENOS was set up in 1993 with the purpose of organising the joint research effort of economists from the two Sardinian universities (Cagliari and Sassari) investigating dualism at the international and regional level. CRENoS' primary aim is to improve knowledge on the economic gap between areas and to provide useful information for policy intervention. Particular attention is paid to the role of institutions, technological progress and diffusion of innovation in the process of convergence or divergence between economic areas. To carry out its research, CRENoS collaborates with research centres and universities at both national and international level. The centre is also active in the field of scientific dissemination, organizing conferences and workshops along with other activities such as seminars and summer schools.

CRENos creates and manages several databases of various socio-economic variables on Italy and Sardinia. At the local level, CRENos promotes and participates to projects impacting on the most relevant issues in the Sardinian economy, such as tourism, environment, transports and macroeconomic forecasts.
\end{abstract}

www.crenos.it

info@crenos.it

CRENOS - CAGLIARI

VIA SAN GIORGIO 12, I.09100 CAGLIARI, ITALIA TEL. + 39.070.6756406; FAX +39.070.6756402

CRENOS - SASSARI

VIA MURONI 23, I.07100 SASSARI, ITALIA TEL. + 39.079.213511

TitIE: LOAN PRODUCTION AND MONETARY POLICY

ISBN: 9788893860062

First Edition: September 2016

Cuec editrice (c) 2016

by Sardegna Novamedia Soc. Coop.

Via Basilicata n.57/59.09127 Cagliari

Tel. e Fax +39070271573 


\title{
Loan production and monetary policy*
}

\author{
Miguel Casares ${ }^{\dagger}$ \\ Luca Deidda \\ Jose E. Galdon-Sanchez ${ }^{\S}$ \\ Universidad Pública de Navarra \\ Università di Sassari \\ Universidad Pública de Navarra
}

\begin{abstract}
We examine optimal monetary policy in a New Keynesian model with unemployment and financial frictions where banks produce loans using equity as collateral. Firms and households demand loans to finance externally a fraction of their flows of expenditures. Our findings show amplifying business-cycle effects of a more rigid loan production technology. In the monetary policy analysis, the optimal rule clearly outperforms Taylor (1993) rule. The optimized interest-rate response to the external finance premium turns significantly negative when either banking rigidities are high or when financial shocks are the only source of business cycle fluctuations.
\end{abstract}

Keywords: external finance, optimal monetary policy, business cycles.

JEL codes: E32, E44.

\section{Introduction}

Macroeconomic models commonly introduce financial frictions by describing agency problems. The seminal contribution to this literature is Townsend (1979), who defines a competitive equilibrium with external finance under asymmetric information and costly state verification. Bernanke and Gertler (1989) develop the financial accelerator mechanism in Townsend (1979)'s framework with overlapping generations: economic expansions increase net worth and reduce auditing costs, which explains amplifying effects on investment. Carlstrom and Fuerst (1997) describe the role of entrepreneurs with random returns in a business cycle model. After observing technology or financial shocks, entrepreneurs borrow from lenders at an interest

\footnotetext{
*All authors are grateful to Banco de España for the grant on the project "Política monetaria en economías con fricciones financieras y bancarias". Miguel Casares and Jose E. Galdon-Sanchez also acknowledge Spanish Ministerio de Economía for research project ECO2015-64330-P. We also thank Bassam Fattouh, Ettore Panetti, Paolo Vitale, William Barnett, and two anonymous referees for useful suggestions and discussions on a previous version of this paper.

${ }^{\dagger}$ Corresponding author. Postal address: Departamento de Economía, Universidad Publica de Navarra, 31006, Pamplona, Spain; Tel.: +34 948169336; Fax: +34 948 169721; E-mail: mcasares@unavarra.es (M. Casares).

${ }^{\ddagger}$ Postal address: Dipartimento di Economia, Impresa, Regolamentazione; Universita di Sassari; Via Torre Tonda 34, 07100, Sassari, Italy. Tel.: +39 3332514329. E-mail: deidda@uniss.it (Luca Deidda).

§Postal address: Postal address: Departmento of Economía, Universidad Pública de Navarra, Campus Arrosadía, 31006, Pamplona (Navarra), Spain. Tel.: +34 948 169338. E-mail: jose.galdon@unavarra.es (Jose E. Galdon-Sanchez).
} 
rate that depends inversely on their net worth and positively on the agency costs. Kiyotaki and Moore (1997) introduce a two-sector model where capital serves as both collateral for borrowing and input for production. The financial friction is then characterized through a collateral constraint that determines the cost of borrowing depending upon the market value of capital.

The interactions between price rigidities and financial frictions were first examined by Bernanke et al. (1999), who show the quantitative implications for the financial accelerator mechanism under sticky prices. A vast literature followed this New Keynesian approach for both business cycles and monetary policy analysis. Faia and Monacelli (2007) examine monetary policy in a model with financial frictions and nominal rigidities. Goodfriend and McCallum (2007) introduce a liquidity (transaction) constraint on consumption spending, and a loan production technology where loans are produced combining monitoring labor and collateralizing assets (capital and bonds). Christiano et al. (2008) extend a DSGE-style model with banking and financial frictions and estimate it for both the US and the Euro Area. The stock of capital, labor and excess reserves are inputs for the production of loans. In addition, firms face a liquidity constraint and must borrow a fraction of their wage and capital rental bills from banks. Cúrdia and Woodford (2010) have two types of household preferences that result in having financial flows running from savers to borrowers. They study unconventional monetary policy rules which may expand central bank credit to offset a disruption of financial intermediation. Gertler and Karadi (2011) assume a moral hazard problem between the bank and the households that makes the balance sheet status of the bank determine the amount of deposits they can get from the households. Angeloni and Faia (2013) build a model with bank runs and describe the way macro-prudential policy can be designed to prevent the economy from falling into a bank crisis. Carlstrom et al. (2014) show that contract indexation improves the fit of the estimated model to actual data and increases the role of investment shocks to explain business cycle fluctuations. Christiano et al. (2014) find that risk shocks (time-varying dispersion in the idiosyncratic shock to the return of investment projects for entrepreneurs) play a major role in the financial accelerator mechanism. Finally, Villa (2016) estimates both the Bernanke et al. (1999) and the Gertler and Karadi (2011) models and finds that the latter provides a better fit to business cycle data of both the US and the Euro Area during the Great Moderation period.

In the flexible-price line of research, Wasmer and Weil (2004) study the interplay between credit and labor market imperfections in a model with matching frictions, and Petrosky-Nadeau and Wasmer (2011) show that a calibrated model with matching frictions in labor, goods and credit markets does a better job than standard search models at replicating the persistence and volatility of unemployment fluctuations. Brunnermeier and Sannikov (2014) find non-linearities and asymmetries on the responses to shocks in a financial economics model with heterogeneous agents and liquidity constraints. They describe the volatility paradox as the persistent endogenous risk, which emerges from the asset illiquidity observed in crisis, even for very low levels of exogenous risk. This phenomenon recommends the use of macro-prudential regulation 
to prevent the economy from the instability obtained when variables jump out of the steady state. ${ }^{1}$

Our paper examines monetary policy in a business cycle model with financial frictions, sticky prices and unemployment. The main contribution of our paper is the analysis of optimal monetary policy in alternative scenarios of banking rigidities or financial shocks. In the model, households and firms face liquidity constraints, whereas banks supply funds using a technology that combines labor and collateral to transform deposits into loans. Both Goodfriend and McCallum (2007) and Christiano et al. (2008) use a Cobb-Douglas loan production function. Our approach introduces two novel features with respect to theirs: firm equity is the asset for banking collateral (instead of capital or bonds) and the elasticity of substitution between inputs can be parameterized at any constant value (which generalizes their unit elasticity of substitution case). Another methodological contribution of our paper is the presence of sticky wages and unemployment, extending the methodology of Casares (2007) to a model with financial frictions.

Even though the model does not incorporate agency costs, the combination of liquidity constraints and a loan production technology results in a financial accelerator mechanism that propagates business cycle fluctuations through changes in both aggregate demand and aggregate supply. Any shock that raises the value of collateral (equity) leads to a lower interest rate charged by the banks that expands both aggregate demand (through the lower cost of borrowing for households' consumption and investment) and aggregate supply (through a lower firms' marginal cost). Hence, the effects of idiosyncratic shocks on output and unemployment are amplified.

We carry out our analysis under two different calibrations of the banking technology. In the baseline calibration, we aim at representing a scenario of macroeconomic stability. Hence, we match some patterns observed in the US during the Great Moderation period, such as long-run values of financial variables and the volatilities observed in aggregate fluctuations of output, inflation and the interest-rate spread. The real effects of the financial accelerator mechanism in the baseline calibration are quantitatively small. However, we find that a low elasticity of substitution between collateral and labor in loan production (rigid banking technology) significantly increases the effects of the financial accelerator on output, unemployment and welfare.

Regarding monetary policy, the central bank implements a Ramsey (1927)-type exercise to determine the optimal monetary policy. Following Woodford (2003)'s quadratic approximation to the household utility function, we derive the welfare-theoretic targeting rule under commitment. Our analysis is in line with that of Faia and Monacelli (2007), although they do not derive explicitly the optimal monetary policy. For a practical (instrument) rule of the central bank, we look for the policy coefficients that define the interest-rate responses to inflation, unemployment and the external finance premium, which best fit the optimal rule. ${ }^{2}$ Under the baseline calibration, we find that the nominal interest rate should be moderately

\footnotetext{
${ }^{1}$ Brunnermeier et al. (2012) make a magnificient survey of the literature on financial frictions in an attempt to bridge the research coming from the fields of macroeconomics and finance.

${ }^{2}$ In Cúrdia and Woodford (2010), a monetary policy rule á la Taylor (1993) is extended to accommodate a policy reaction to
} 
increased whenever either inflation is high or unemployment is low, with no significant response to the external finance premium. This result, however, changes dramatically when assuming a rigid banking technology. In this case, the central bank would pursue optimal monetary policy by cutting interest rates when the external finance premium rises. Our results also indicate that banking rigidities reduce substantially the level of social welfare. As the financial accelerator amplifies business cycle fluctuations, the volatilities of both consumption and leisure rise and household welfare falls. Thus, the optimal policy prescription should include a significant reversed-sign response of the nominal interest rate to the external finance premium. In another simulation exercise, we test the behavior of the optimal monetary policy when the business cycle is exclusively generated by financial shocks. We find that, in this case, the central bank should be more aggressive in response to inflation, unemployment and the external finance premium. The consequences of banking rigidities for social welfare are more harmful than in the multi-shock scenario.

The rest of the paper is organized as follows. Section 2 describes the model, including the optimal monetary policy. Section 3 is devoted to the baseline calibration of model parameters. In Section 4, we carry out the monetary policy analysis that discusses the optimal design of instrument rules extended with response coefficients to the external finance premium. Section 5 concludes.

\section{The model}

We consider a closed-economy populated by a continuum of size one of infinitely-lived identical households, who own a continuum of size one of both monopolistically competitive firms and competitive banks. In each period $t$, households supply labor to firms and banks, demand loans, and allocate their resources to consumption, purchases of financial assets -such as deposits and firm's equity-, and physical capital. Simultaneously, firms demand labor, capital, and loans in order to produce a differentiated good with nominal rigidities on the process of setting both prices and wages. Banks issue deposits to finance themselves, demand labor and collateral - in the form of firm's equity - and use these inputs to produce loans. The central bank acts as a social planner that designs the welfare-maximizing monetary policy. We now examine the behavior of each representative agent.

\subsection{Households}

At any period $t$, the representative household is endowed with the following stock of wealth

$$
x_{t} v_{t}+d_{t}+k_{t}
$$

where $v_{t}$ is the aggregate real value of equity, $x_{t}$ is the fraction of equity owned, $d_{t}$ is her stock of real bank deposits, and $k_{t}$ is capital. Household's preferences are described by the following instantaneous utility changes in the external finance premium. The interest-rate rule proposed in Angeloni and Faia (2013) incorporates responses to both asset prices and the ratio of deposits over loans. 
function

$$
\frac{c_{t}^{1-\sigma}}{1-\sigma}+\Psi \frac{\left(1-n_{t}^{s}-m_{t}^{s}\right)^{1-\gamma}}{1-\gamma}
$$

where $c_{t}$ is the amount of consumption of a Dixit and Stiglitz (1977) basket of differentiated goods, the time endowment equals 1 , and $n_{t}^{s}$ and $m_{t}^{s}$ are labor services supplied to firms and banks, respectively; so that $1-n_{t}^{s}-m_{t}^{s}$ is leisure time. The parameter $\Psi>0$ determines the weight of leisure on total utility, whereas $\sigma, \gamma>0$ are respectively the elasticities of the consumption and leisure marginal utilities.

There are wage rigidities and unemployment in the firm's labor market, but not in the bank's labor market. Hence, the effective labor income from working at the firms is $\frac{w_{t} n_{t}^{s}}{1+u_{t}}$, where $w_{t}$ is the real wage and $u_{t}$ is the unemployment rate, whereas $w_{t}^{m} m_{t}^{s}$ is the labor income from working at the banking sector at the real wage rate $w_{t}^{m}$. The representative household receives $r_{t}^{k} k_{t}$ from renting capital $k_{t}$ to firms at the real rate, $r_{t}^{k}$; collects a share $x_{t}$ of aggregate real dividends, $e_{t}$; obtains a real interest rate of $r_{t-1}^{d}$ per unit of bank real deposits, $d_{t}$; and a collateral service real yield, csyt, per unit of real equity holdings, $x_{t} v_{t}$. Income is spent on consumption goods, capital accumulation, equity holdings, bank deposits, and the interest payments of bank loans. For an investment function on capital goods, we use the specification with adjustment costs described by Woodford (2003), that determines the amount of spending required to increase the stock of capital from $k_{t}$ to $k_{t+1}$ as an increasing function of their ratio, $I\left(\frac{k_{t+1}}{k_{t}}\right) \cdot{ }^{3}$ The stock of capital is one-period predetermined. Regarding the cost of external finance, let $r_{t}^{l}$ be the real interest rate on loans and $l_{t}^{h}$ the amount of real loans demanded by the household. Thus, the household's budget constraint in real terms becomes

$$
\left(\frac{w_{t} n_{t}^{s}}{1+u_{t}}+w_{t}^{m} m_{t}^{s}\right)+r_{t}^{k} k_{t}+x_{t} e_{t}+r_{t-1}^{d} d_{t}+c s y_{t} x_{t} v_{t}=c_{t}+I\left(\frac{k_{t+1}}{k_{t}}\right) k_{t}+\left(x_{t+1}-x_{t}\right) v_{t}+\left(d_{t+1}-d_{t}\right)+r_{t}^{l} l_{t}^{h}
$$

Within each period $t$, we assume that there is a mismatch between the time at which household's financial needs emerge and the time at which household's financial resources materialize. More precisely, households borrow at the beginning of the period the amount $l_{t}^{h}$ that results from their deficit of financial resources. When the surplus of financial resources arrives, they use their savings to make the asset portfolio choice for the next period (optimal amounts of bank deposits, $d_{t+1}$, equity holdings, $x_{t+1}$, and capital, $k_{t+1}$ ). Hence, the liquidity constraint that gives rise to the household's demand for real bank loans is

$$
l_{t}^{h}=\tau_{h}\left(c_{t}+I\left(\frac{k_{t+1}}{k_{t}}\right) k_{t}\right)
$$

where $0<\tau_{h}<1$ is the constant share of spending to be financed externally. In period $t$, given a constant discount factor $\beta=(1+\rho)^{-1}$, with a rate of intertemporal preference $\rho>0$, the representative household chooses $c_{t}, n_{t}^{s}, m_{t}^{s}, k_{t+1}, x_{t+1}, d_{t+1}$, and $l_{t}^{h}$, so as to maximize intertemporal utility subject to (3) and (4). ${ }^{4}$

\footnotetext{
${ }^{3}$ In a steady state with no growth, the unit cost of investment is $I(1)=\delta$, where $\delta$ is the constant rate of capital depreciation. The first and second derivatives in steady state are $I^{\prime}(1)=1$ and $I^{\prime \prime}(1)=\epsilon$, where $\epsilon>0$ is the parameter that defines the adjustment cost elasticity.

${ }^{4}$ Households also choose the composition of the bundles of consumption and labor supply in relative terms to the $\omega$ good variety, $c_{t}(\omega)$ and $n_{t}^{s}(\omega)$. These optimal choices are shown respectively in Sections 1 and 2 of the Appendix.
} 
The first order conditions of the household maximization problem are

$$
\begin{gathered}
c_{t}^{-\sigma}-\lambda_{t}-\zeta_{t} \tau_{h}=0 \\
-\Psi\left(1-n_{t}^{s}-m_{t}^{s}\right)^{-\gamma}+\lambda_{t} \frac{w_{t}}{1+u_{t}}=0 \\
-\Psi\left(1-n_{t}^{s}-m_{t}^{s}\right)^{-\gamma}+\lambda_{t} w_{t}^{m}=0 \\
-\left(\lambda_{t}+\zeta_{t} \tau_{h}\right) I^{\prime}\left(\frac{k_{t+1}}{k_{t}}\right)+\beta E_{t}\left[\lambda_{t+1} r_{t+1}^{k}-\left(\lambda_{t+1}+\zeta_{t+1} \tau_{h}\right)\left(I^{\prime}\left(\frac{k_{t+2}}{k_{t+1}}\right)\left(\frac{-k_{t+2}}{k_{t+1}}\right)+I\left(\frac{k_{t+2}}{k_{t+1}}\right)\right)\right]=0 \\
-\lambda_{t} v_{t}+\beta E_{t} \lambda_{t+1}\left[e_{t+1}+v_{t+1}\left(1+c s y_{t+1}\right)\right]=0 \\
-\lambda_{t}+\beta E_{t} \lambda_{t+1}\left(1+r_{t}^{d}\right)=0 \\
-\lambda_{t} r_{t}^{l}+\zeta_{t}=0
\end{gathered}
$$

where $\lambda_{t}$ and $\zeta_{t}$ denote the Lagrange multipliers associated with the budget constraint (3) and the demand for loans (4), respectively. In addition, $E_{t}$ is the rational expectation operator conditional to the information set available in period $t$. Note that, given the first order conditions, the following relationship holds

$$
\left(1+r_{t}^{d}\right)^{-1}=\frac{\beta E_{t} \lambda_{t+1}}{\lambda_{t}}=\beta_{t, t+1}
$$

where $\beta_{t, t+1}$ is the stochastic discount factor between periods $t$ and $t+1$, and the Lagrange multiplier is the marginal utility of consumption penalized by the unit cost of borrowing

$$
\lambda_{t}=\frac{c_{t}^{-\sigma}}{1+\tau_{h} r_{t}^{l}}
$$

Combining first order conditions of equity holdings and deposits leads to the following equation for the dynamics of real equity value

$$
v_{t}=\beta\left(1+r_{t}^{d}\right)^{-1} E_{t}\left[e_{t+1}+v_{t+1}\left(1+c s y_{t+1}\right)\right]
$$

which entails a higher equity value, $v_{t}$, when the collateral service yield of equity holdings for the next period, $c s y_{t+1}$, is expected to rise.

Household's dependence on external finance, as defined by (4), implies dynamic responses of consumption, capital accumulation and labor supply to the cost of borrowing. Hence, the expressions that govern such decisions can be obtained from combining and log-linearizing the first order conditions. Using hattype labels to denote $\log$ deviations from their steady state levels (e.g., $\widehat{c}_{t}=\ln \left(\frac{c_{t}}{c}\right)$, where $c$ is the constant level of consumption in steady state), the semi-loglinear expressions that we obtain are

$$
\begin{aligned}
\widehat{c}_{t} & =E_{t} \widehat{c}_{t+1}-\frac{1}{\sigma}\left(r_{t}^{d}-\rho\right)-\frac{\tau_{h}}{\sigma}\left(r_{t}^{l}-E_{t} r_{t+1}^{l}\right) \\
\widehat{k}_{t+1} & =\frac{1}{1+\beta} \widehat{k}_{t}+\frac{\beta}{1+\beta} E_{t} \widehat{k}_{t+2}+\frac{1}{(1+\beta) \epsilon}\left(\left(E_{t} r_{t+1}^{k}-r^{k}\right)-\left(r_{t}^{d}-\rho\right)-\tau_{h}\left(r_{t}^{l}-E_{t} r_{t+1}^{l}\right)\right) \\
\frac{n}{1-n-m} \widehat{n}_{t}^{s}+\frac{m}{1-n-m} \widehat{m}_{t} & =\frac{1}{\gamma}\left(\widehat{w}_{t}-u_{t}-\sigma \widehat{c}_{t}-\tau_{h}\left(r_{t}^{l}-r^{l}\right)\right)
\end{aligned}
$$

Subsequently, the cost of borrowing, $r_{t}^{l}$, has a negative impact on consumption, capital accumulation and labor supply. If the external finance requirement is removed $\left(\tau_{h}=0\right)$, household's decisions would be 
independent of the cost of borrowing, and consumption, capital accumulation and labor supply dynamics would be the same as in a model without banking.

\section{$2.2 \quad$ Firms}

Firm $\omega$ specializes in the production of one differentiated consumption good, using a Cobb-Douglas production technology. In period $t$, the production function is

$$
y_{t}(\omega)=e^{\varepsilon_{t}^{z}} k_{t}(\omega)^{\alpha} n_{t}(\omega)^{1-\alpha}
$$

where $y_{t}(\omega), k_{t}(\omega)$ and $n_{t}(\omega)$ are, respectively, the amounts of firm-specific output, capital demand and labor demand. In addition, $\varepsilon_{t}^{z}$ is an exogenous $\operatorname{AR}(1)$ economy-wide productivity shock, and $0<\alpha<1$ is a parameter that defines the capital elasticity of output. As in Dixit and Stiglitz (1977), firm $\omega$ faces the following market demand in monopolistic competition

$$
y_{t}(\omega)=\left(\frac{P_{t}(\omega)}{P_{t}}\right)^{-\theta_{p}} y_{t}
$$

where $\theta_{p}>0$ is the Dixit-Stiglitz constant elasticity of substitution across consumption goods, $P_{t}(\omega)$ is the price of the good produced by the $\omega$ firm, $P_{t}$ is the Dixit-Stiglitz aggregate price level, and $y_{t}$ is the Dixit-Stiglitz aggregate output.

We assume that firms must borrow liquidity in order to finance a fraction $\tau_{f}$ of their variable cost of production. Let $\frac{W_{t}(\omega)}{P_{t}}$ be the specific real wage of the $\omega$ firm. Then, its demand for real loans, $l_{t}^{f}(\omega)$, is

$$
l_{t}^{f}(\omega)=\tau_{f}\left(\frac{W_{t}(\omega)}{P_{t}} n_{t}(\omega)+r_{t}^{k} k_{t}(\omega)\right)
$$

Real loans must be reimbursed to the banks by the end of the period. Given $r_{t}^{l}$, loan repayments by firm $\omega$ amount to $r_{t}^{l} l_{t}^{f}(\omega)$, and its real earnings $\operatorname{are}^{5}$

$$
e_{t}(\omega)=\frac{P_{t}(\omega)}{P_{t}} y_{t}(\omega)-\frac{W_{t}(\omega)}{P_{t}} n_{t}(\omega)-r_{t}^{k} k_{t}(\omega)-r_{t}^{l} l_{t}^{f}(\omega)
$$

where substituting equation (7) yields

$$
e_{t}(\omega)=\frac{P_{t}(\omega)}{P_{t}} y_{t}(\omega)-\left(1+\tau_{f} r_{t}^{l}\right)\left(\frac{W_{t}(\omega)}{P_{t}} n_{t}(\omega)+r_{t}^{k} k_{t}(\omega)\right)
$$

\section{Wage rigidity}

Sticky wages are introduced by assuming a Calvo (1983) lottery, whereby households and firms have a constant probability $\eta$ of not being able to revise the wage of their labor contracts. ${ }^{6}$ This lottery generates firm's heterogeneity in the nominal wage, $W_{t}(\omega)$, and the labor demand, $n_{t}(\omega)$, as well as household's

\footnotetext{
${ }^{5}$ A log-linear version of firm earnings is obtained in Section 3 of the Appendix.

${ }^{6}$ As in Casares (2007), wage stickiness is subject to the same lottery that governs the price stickiness introduced below.
} 
heterogeneity in the labor supply, $n_{t}^{s}(\omega)$. Following Casares (2007), the nominal wage is revised in order to make the intertemporal labor demand equal to the intertemporal labor supply at the firm level. If the $\omega$ firm receives a Calvo signal at time $t$, the revision of the nominal wage would be determined as follows

$$
\sum_{j=0}^{\infty} E_{t}^{\eta}(\beta \eta)^{j}\left(\widehat{n}_{t+j}(\omega)-\widehat{n}_{t+j}^{s}(\omega)\right)=0
$$

where, $E_{t}^{\eta}$ is the rational expectation operator conditional on not receiving a Calvo signal for wage revisions in the future, and $\left(\widehat{n}_{t+j}(\omega)-\widehat{n}_{t+j}^{s}(\omega)\right)$ represents the log deviation between the labor demand and labor supply in firm $\omega$ at period $t+j$, with $j=0,1,2, \ldots, \infty$. If wage stickiness were eliminated $(\eta=0)$, the wage setting condition (9) would imply a perfect matching between firm-level labor supply and labor demand, $n_{t}(\omega)=n_{t}^{s}(\omega) .^{7}$ Hence, nominal rigidities in wage setting open a gap between labor supply and labor demand at firm level. ${ }^{8}$

The value of $W_{t}(\omega)$ required to hold (9) depends on the intertemporal labor demand and supply. The optimal labor supply allocation of the representative household implies ${ }^{9}$

$$
\widehat{n}_{t}^{s}(\omega)=\theta_{w} \widetilde{W}_{t}(\omega)+\widehat{n}_{t}^{s}
$$

where $\widetilde{W}_{t}(\omega)=\widehat{W}_{t}(\omega)-\widehat{W}_{t}$ is the relative nominal wage at firm $\omega$ with respect to the Dixit-Stiglitz aggregate nominal wage, $\theta_{w}>0$ is the Dixit-Stiglitz constant elasticity of substitution across different types of labor supplied to firms, and $\widehat{n}_{t}^{s}$ is the log fluctuation of the aggregate labor supply to firms. Meanwhile, firm $\omega$ labor demand is

$$
\widehat{n}_{t}(\omega)=-\theta_{p} \widetilde{P}_{t}(\omega)-\alpha \widetilde{W}_{t}(\omega)+\widehat{n}_{t}
$$

where $\widetilde{P}_{t}(\omega)=\widehat{P}_{t}(\omega)-\widehat{P}_{t}$ is the relative price, and $\widehat{n}_{t}$ is the log fluctuation of aggregate labor demand. Generalizing (10) and (11) for future periods and plugging them into (9) lead to

$$
\sum_{j=0}^{\infty} E_{t}^{\eta}(\beta \eta)^{j}\left(-\theta_{p} \widetilde{P}_{t+j}(\omega)-\left(\alpha+\theta_{w}\right) \widetilde{W}_{t+j}(\omega)-u_{t+j}\right)=0
$$

where we have inserted the definition of the rate of unemployment as the aggregate excess supply of labor

$$
u_{t+j}=\widehat{n}_{t+j}^{s}-\widehat{n}_{t+j}
$$

Let $\pi_{t}=\widehat{P}_{t}-\widehat{P}_{t-1}$ and $\pi_{t}^{w}=\widehat{W}_{t}-\widehat{W}_{t-1}$ denote respectively price inflation and wage inflation in period $t$. If the Calvo signal does not give the firm a chance to price optimally, firms adjust the previous price as determined by the following price indexation rule

$$
P_{t}(.)=P_{t-1}(.)\left(1+\pi+\varepsilon_{t}^{p}\right)
$$

\footnotetext{
${ }^{7}$ This would be the case for an economy with heterogeneous labor and flexible wages of the kind described in Woodford (2003), chapter 3 .

${ }^{8}$ Labor fluctuations are considered at the employment level (extensive margin) in order to provide a fundamental interpretation of unemployment. Hours per worker (intensive margin) are fixed.

${ }^{9}$ See Section 2 of the Appendix for the proof and further details.
} 
where $\pi$ denotes the steady-state rate of price inflation, and $\varepsilon_{t}^{p}$ is an $\operatorname{AR}(1)$ exogenous price-push shock. Then, Calvo-type rigidities and price indexation imply that the conditional expectations of relative prices and wages are, respectively, $E_{t}^{\eta} \widetilde{P}_{t+j}(\omega)=\widetilde{P}_{t}(\omega)-\sum_{k=1}^{j} E_{t}\left(\left(\pi_{t+k}-\pi\right)-\varepsilon_{t+k}^{p}\right)$ and $E_{t}^{\eta} \widetilde{W}_{t+j}(\omega)=\widetilde{W}_{t}(\omega)-$ $\sum_{k=1}^{j} E_{t}\left(\pi_{t+k}^{w}-\pi^{w}\right)$, which can be used in (12) to obtain

$$
\widetilde{W}_{t}(\omega)=\sum_{j=1}^{\infty} E_{t} \beta^{j} \eta^{j}\left(\pi_{t+j}^{w}-\pi^{w}\right)-\frac{\theta_{p}}{\alpha+\theta_{w}}\left(\widetilde{P}_{t}(\omega)-\sum_{j=1}^{\infty} E_{t} \beta^{j} \eta^{j}\left(\left(\pi_{t+j}-\pi\right)-\varepsilon_{t+j}^{p}\right)\right)-\frac{1-\beta \eta}{\alpha+\theta_{w}} \sum_{j=0}^{\infty} E_{t} \beta^{j} \eta^{j} u_{t+j}
$$

As indicated in (14), the relative wage $\widetilde{W}_{t}(\omega)$ depends negatively on the relative price $\widetilde{P}_{t}(\omega)$. Thus, the price setting behavior must be now discussed in order to derive an expression for $\widetilde{P}_{t}(\omega)$.

\section{Price rigidity}

Price setting is constrained by the same Calvo (1983) lottery as wage setting. If the market signal for optimal pricing arrives, firm $\omega$ will choose $P_{t}(\omega), k_{t}(\omega)$ and $n_{t}(\omega)$ to maximize the intertemporal earnings, $\sum_{j=0}^{\infty} E_{t} \beta_{t, t+j} e_{t+j}(\omega)$, where $\beta_{t, t+j}=\prod_{k=0}^{j-1}\left(1+r_{t+k}^{d}\right)^{-1}$ is the stochastic discount factor from period $t$ to period $t+j$, subject to the Dixit-Stiglitz demand constraints and the Cobb-Douglas production technology. In turn, the optimal choices of $P_{t}(\omega), k_{t}(\omega)$ and $n_{t}(\omega)$ satisfy the following first order conditions

$$
\begin{gathered}
\sum_{j=0}^{\infty} E_{t}^{\eta} \beta_{t, t+j} \eta^{j}\left(\begin{array}{c}
\left(1-\theta_{p}\right)\left(\frac{P_{t}(\omega) \Pi_{t, t+j}^{p}}{P_{t+j}}\right)^{-\theta_{p}} \frac{y_{t+j} \Pi_{t, t+j}^{p}}{P_{t+j}}-\left(1+\tau_{f} r_{t}^{l}\right) \frac{\partial W_{t}(\omega)}{\partial P_{t}(\omega)} \frac{n_{t+j}(\omega)}{P_{t+j}} \\
+\xi_{t+j}(\omega) \theta_{p}\left(\frac{P_{t}(\omega) \Pi_{t, t+j}^{p}}{P_{t+j}}\right)^{-\theta_{p}-1} \frac{y_{t+j} \Pi_{t, t+j}^{p}}{P_{t+j}}
\end{array}\right)=0 \\
-\left(1+\tau_{f} r_{t}^{l}\right) \frac{W_{t}(\omega)}{P_{t}}+\xi_{t}(\omega) \frac{(1-\alpha) y_{t}(\omega)}{n_{t}(\omega)}=0 \\
-\left(1+\tau_{f} r_{t}^{l}\right) r_{t}^{k}+\xi_{t}(\omega) \frac{\alpha y_{t}(\omega)}{k_{t}(\omega)}=0
\end{gathered}
$$

where $\xi_{t+j}(\omega)$ is the Lagrange multiplier associated with the demand constraint (6) in any $t+j$ period, and $\Pi_{t, t+j}^{p}=\prod_{k=1}^{j}\left(1+\pi+\varepsilon_{t+k}^{p}\right)$ is the price indexation factor between $t$ and $t+j$ consistent with the indexation rule. Combining (16) and (17), we obtain that $\xi_{t}(\omega)$ is equal to the real marginal cost of production

$$
\xi_{t}(\omega)=\alpha^{-\alpha}(1-\alpha)^{-(1-\alpha)}\left(1+\tau_{f} r_{t}^{l}\right) e^{-\varepsilon_{t}^{z}}\left(\frac{W_{t}(\omega)}{P_{t}}\right)^{1-\alpha}\left(r_{t}^{k}\right)^{\alpha}
$$

that, remarkably, incorporates the cost of borrowing, $\left(1+\tau_{f} r_{t}^{l}\right)$. From the log-linear equation (14) of the previous subsection, we have a constant (negative) wage-price elasticity $\frac{\partial W_{t}(\omega)}{\partial P_{t}(\omega)} \frac{W_{t}(\omega)}{P_{t}(\omega)}=-\frac{\theta_{p}}{\alpha+\theta_{w}}$. Using this result, the demand constraint (6) generalized for $t+j$ periods, and equation (18) also generalized for any $t+j$ periods, the first order condition (15) becomes

$\sum_{j=0}^{\infty} E_{t}^{\eta} \beta_{t+j} \eta^{j}\left(\left(1-\theta_{p}\right)\left(\frac{P_{t}(\omega) \Pi_{t, t+j}^{p}}{P_{t+j}}\right)^{-\theta_{p}} \frac{y_{t+j} \Pi_{t, t+j}^{p}}{P_{t+j}}+\xi_{t+j}(\omega) \theta_{p}\left(1+\frac{1-\alpha}{\alpha+\theta_{w}}\right)\left(\frac{P_{t}(\omega) \Pi_{t, t+j}^{p}}{P_{t+j}}\right)^{-\theta_{p}-1} \frac{y_{t+j} \Pi_{t, t+j}^{p}}{P_{t+j}}\right)=0$ 
where solving for the optimal price yields

$$
P_{t}(\omega)=\frac{\theta_{p}\left(1+\frac{1-\alpha}{\alpha+\theta_{w}}\right)}{\theta_{p}-1}\left[\frac{\sum_{j=0}^{\infty} E_{t}^{\eta} \beta_{t+j} \eta^{j} \xi_{t+j}(\omega)\left(P_{t+j}\right)^{\theta_{p}}\left(\Pi_{t, t+j}^{p}\right)^{-\theta_{p}} y_{t+j}}{\sum_{j=0}^{\infty} E_{t}^{\eta} \beta_{t+j} \eta^{j}\left(P_{t+j}\right)^{\theta_{p}-1}\left(\Pi_{t, t+j}^{p}\right)^{1-\theta_{p}} y_{t+j}}\right]
$$

Following Walsh (2010) and noticing the price indexation rule, the optimal price (19) can be approximated by the semi-loglinear expression for the relative price

$$
\widetilde{P}_{t}(\omega)=(1-\beta \eta) \sum_{j=0}^{\infty} E_{t}^{\eta}(\beta \eta)^{j}\left(\widehat{\xi}_{t+j}(\omega)+\sum_{k=1}^{j}\left(\left(\pi_{t+k}-\pi\right)-\varepsilon_{t+k}^{p}\right)\right)
$$

which is equivalent to

$$
\widetilde{P}_{t}(\omega)=(1-\beta \eta) \sum_{j=0}^{\infty} E_{t}^{\eta}(\beta \eta)^{j} \widehat{\xi}_{t+j}(\omega)+\sum_{j=1}^{\infty} E_{t}^{\eta}(\beta \eta)^{j}\left(\left(\pi_{t+j}-\pi\right)-\varepsilon_{t+j}^{p}\right)
$$

Let $\widetilde{\xi}_{t+j}(\omega)=\widehat{\xi}_{t+j}(\omega)-\widehat{\xi}_{t+j}$ be the relative real marginal cost for firm $\omega$ in period $t+j$. Taking $\operatorname{logs}$ and subtracting the log of aggregate variables, relation (18) implies

$$
E_{t}^{\eta} \widetilde{\xi}_{t+j}(\omega)=(1-\alpha) E_{t}^{\eta} \widetilde{W}_{t+j}(\omega)
$$

Plugging $E_{t}^{\eta} \widetilde{W}_{t+j}(\omega)=\widetilde{W}_{t}(\omega)-\sum_{k=1}^{j} E_{t} \pi_{t+k}^{w}$ in the previous equation and the expression $\widehat{\xi}_{t+j}(\omega)=$ $\widetilde{\xi}_{t+j}(\omega)+\widehat{\xi}_{t+j}$ in $(20)$ lead to

$$
\begin{aligned}
\widetilde{P}_{t}(\omega)=(1-\beta \eta) \sum_{j=0}^{\infty} E_{t}^{\eta}(\beta \eta)^{j}\left(\widehat{\xi}_{t+j}+(1-\alpha)\left(\widetilde{W}_{t}(\omega)-\sum_{k=1}^{j} E_{t} \pi_{t+k}^{w}\right)\right) & \\
& +\sum_{j=1}^{\infty} E_{t}^{\eta}(\beta \eta)^{j}\left(\left(\pi_{t+j}-\pi\right)-\varepsilon_{t+j}^{p}\right)
\end{aligned}
$$

or the equivalent (simpler) expression for relative prices

$$
\widetilde{P}_{t}(\omega)=(1-\alpha) \widetilde{W}_{t}(\omega)+(1-\beta \eta) \sum_{j=0}^{\infty} E_{t}^{\eta}(\beta \eta)^{j} \widehat{\xi}_{t+j}+\sum_{j=1}^{\infty} E_{t}^{\eta}(\beta \eta)^{j}\left(\left(\pi_{t+j}-\pi\right)-\varepsilon_{t+j}^{p}-(1-\alpha) \pi_{t+j}^{w}\right)
$$

New Keynesian Phillips Curves

As a well-known result, Calvo-type rigidities imply a proportional relationship between relative prices and the rate of inflation. For both prices and nominal wages, we respectively have

$$
\widetilde{P}_{t}(\omega)=\frac{\eta}{1-\eta}\left(\left(\pi_{t}-\pi\right)-\varepsilon_{t}^{p}\right) \text { and } \widetilde{W}_{t}(\omega)=\frac{\eta}{1-\eta}\left(\pi_{t}^{w}-\pi^{w}\right)
$$

which can jointly be plugged in (21) to reach

$$
\begin{aligned}
\left(\pi_{t}-\pi\right)-\varepsilon_{t}^{p}=(1-\alpha)\left(\pi_{t}^{w}-\pi^{w}\right)+\frac{(1-\beta \eta)(1-\eta)}{\eta} & \sum_{j=0}^{\infty} E_{t}^{\eta}(\beta \eta)^{j} \widehat{\xi}_{t+j} \\
& +\frac{(1-\eta)}{\eta} \sum_{j=1}^{\infty} E_{t}^{\eta}(\beta \eta)^{j}\left(\left(\pi_{t+j}-\pi\right)-\varepsilon_{t+j}^{p}-(1-\alpha) \pi_{t+j}^{w}\right)
\end{aligned}
$$


Taking the difference $\left(\pi_{t}-\pi\right)-\beta \eta E_{t}\left(\pi_{t+1}-\pi\right)$, results in the following price inflation equation

$$
\pi_{t}-\pi=\beta E_{t}\left(\pi_{t+1}-\pi\right)+(1-\alpha)\left(\left(\pi_{t}^{w}-\pi^{w}\right)-\beta E_{t}\left(\pi_{t+1}^{w}-\pi^{w}\right)\right)+\frac{(1-\beta \eta)(1-\eta)}{\eta} \widehat{\xi}_{t}+\left(\varepsilon_{t}^{p}-\beta E_{t} \varepsilon_{t+1}^{p}\right)
$$

Let us now recall the relative wage setting obtained in (14) where there is an inverse relation between wage and price setting. Using the expressions of both $\widetilde{P}_{t}(\omega)$ and $\widetilde{W}_{t}(\omega)$ from $(22)$ and plugging them in (14) gives the wage inflation equation

$$
\begin{aligned}
\left(\pi_{t}^{w}-\pi^{w}\right)=\frac{1-\eta}{\eta} \sum_{j=1}^{\infty} E_{t} \beta^{j} \eta^{j} \pi_{t+j}^{w}\left(\pi_{t+j}^{w}-\pi^{w}\right)-\frac{(1-\beta \eta)(1-\eta)}{\eta\left(\alpha+\theta_{w}\right)} \sum_{j=0}^{\infty} E_{t} \beta^{j} \eta^{j} u_{t+j}-\frac{\theta_{p}}{\alpha+\theta_{w}}\left(\left(\pi_{t}-\pi\right)-\varepsilon_{t}^{p}\right) & \\
& +\frac{\theta_{p}(1-\eta)}{\eta(\alpha+\theta w)} \sum_{j=1}^{\infty} E_{t} \beta^{j} \eta^{j}\left(\left(\pi_{t+j}-\pi\right)-\varepsilon_{t+j}^{p}\right)
\end{aligned}
$$

where taking the first difference, $\pi_{t}^{w}-\beta \eta E_{t} \pi_{t+1}^{w}$, we obtain

$$
\left(\pi_{t}^{w}-\pi^{w}\right)=\beta E_{t}\left(\pi_{t+1}^{w}-\pi^{w}\right)-\frac{(1-\beta \eta)(1-\eta)}{\eta\left(\alpha+\theta_{w}\right)} u_{t}-\frac{\theta_{p}}{\alpha+\theta_{w}}\left(\left(\left(\pi_{t}-\pi\right)-\varepsilon_{t}^{p}\right)-\beta E_{t}\left(\left(\pi_{t+1}^{p}-\pi^{p}\right)-\varepsilon_{t+1}^{p}\right)\right)
$$

Inserting in (24) the expression of $\left(\pi_{t}-\pi\right)-E_{t} \beta\left(\pi_{t+1}-\pi\right)$ obtained in (23) brings, after some rearranging, the wage inflation equation

$$
\pi_{t}^{w}-\pi^{w}=\beta E_{t}\left(\pi_{t+1}^{w}-\pi^{w}\right)-\frac{(1-\eta)(1-\beta \eta)}{\eta\left(\alpha+\theta_{w}+\theta_{p}(1-\alpha)\right)}\left(u_{t}+\theta_{p} \widehat{\xi}_{t}\right)
$$

Expression (25) somehow resembles an old-fashion Phillips curve in the negative relationship between wage inflation, $\pi_{t}^{w}$, and the rate of unemployment, $u_{t}$. There is also some negative effect from fluctuations in the real marginal cost (and thus the firm cost of borrowing) as a consequence of the interdependence between wage setting and pricing. An increase in firm-specific marginal costs would raise the relative price and reduce relative labor demand, which would push nominal wages downwards according to (9).

Finally, the value $\left(\pi_{t}^{w}-\pi^{w}\right)-\beta E_{t}\left(\pi_{t+1}^{w}-\pi^{w}\right)$ implied by (24) can be used in the inflation equation (23) to derive a New Keynesian Phillips Curve (NKPC)

$$
\pi_{t}-\pi=\beta E_{t}\left(\pi_{t+1}-\pi\right)+\frac{(1-\eta)(1-\beta \eta)\left(\alpha+\theta_{w}\right)}{\eta\left(\alpha+\theta_{w}+\theta_{p}(1-\alpha)\right)}\left(\widehat{\xi}_{t}-\frac{(1-\alpha)}{\left(\alpha+\theta_{w}\right)} u_{t}\right)+\left(1-\beta \rho_{p}\right) \varepsilon_{t}^{p}
$$

where price inflation is forward looking and depends on the fluctuations of the aggregate real marginal cost, $\widehat{\xi}_{t}$, on the rate of unemployment, $u_{t}$, and on the price-push shock, $\varepsilon_{t}^{p}$. Unlike other NKPC existing in the literature, the presence of $u_{t}$ is explained by its influence on the wage setting and therefore on the optimal price setting. ${ }^{10}$ In addition, financial frictions have an indirect influence in the dynamics of the NKPC because the real interest rate on loans, $r_{t}^{l}$, is one of the variables that determine fluctuations in the aggregate real marginal cost

$$
\widehat{\xi}_{t}=\tau_{f}\left(r_{t}^{l}-r^{l}\right)+(1-\alpha) \widehat{w}_{t}+\frac{\alpha}{r^{k}}\left(r_{t}^{k}-r^{k}\right)-\varepsilon_{t}^{z}
$$

\footnotetext{
${ }^{10}$ The firm-specific nominal wage depends negatively on firm-level unemployment and determines the firm-specific real marginal cost. As firms set prices by foreseeing current and expected future fluctuations on real marginal costs, an increase in the rate of unemployment will have deflationary effects.
} 


\subsection{Banks}

There is a perfectly competitive banking industry that provides external finance to households and firms. Banks issue deposits as its source of funding, and they employ some labor for the monitoring of the actual value of the borrowers' collateral. Hence, in period $t$, the representative bank uses a technology of loan production that combines labor, $m_{t}$, and the real value of equity, $v_{t}$, which it is the asset used as collateral, to transform the amount of real deposits $d_{t}$, into real loans, $l_{t}$.

In line with agency costs models (Townsend, 1979; Bernanke and Gertler, 1989), the loan production function may be interpreted as a reduced form that captures the fact that - in the presence of informational asymmetries - both labor-intensive monitoring services and collateral play a crucial role in: (i) aligning borrowers' and lenders' incentives, i.e. ameliorating moral hazard, and/or (ii) providing information about borrowers' characteristics, i.e. reducing adverse selection, so that, other things equal, the amount of loans that a bank is willing to supply increases with both of them. Our loan production technology takes the following constant elasticity of substitution (CES) specification

$$
l_{t}=d_{t} B\left[a\left(e^{\varepsilon_{t}^{l}} v_{t}\right)^{\chi}+(1-a) m_{t}^{\chi}\right]^{\frac{1}{\chi}}
$$

where $B>0$ is the scale parameter, $-\infty<\chi \leq 1$ is the elasticity parameter, $0<a<1$ is the weight of collateral, and $\varepsilon_{t}^{l}$ is an exogenous $\operatorname{AR}(1)$ collateral-augmenting shock. The elasticity of substitution between collateral, $v_{t}$, and bank labor, $m_{t}$, is constant at $\frac{1}{1-\chi}$. This brings the upper bound, $\chi=1$, when loan production converges to a linear function with perfect substitutability between the two factors (infinite elasticity). When $\chi$ approaches to its lower bound, $\chi=-\infty$, the loan production function turns into a Leontief technology, with no substitutability (zero elasticity). As an intermediate case, the Cobb-Douglas technology is particularized by (26) when $\chi$ approaches to 0 and there is a unit elasticity of substitution (as in Goodfriend and McCallum, 2007; and Christiano et al., 2008).

The amount of deposits is demand-determined, given the real interest rate on deposits, $r_{t}^{d}=R_{t}-E_{t} \pi_{t+1}$, where $R_{t}$ is the nominal interest rate set by the central bank. Banks must serve $r_{t-1}^{d}$ per unit of real deposit taken, and receive $r_{t}^{l}$ per unit of real loan. Hence, the profit function of the representative bank can be written as follows

$$
r_{t}^{l} l_{t}-c s y_{t} v_{t}-w_{t}^{m} m_{t}-r_{t-1}^{d} d_{t}
$$

Abstracting from bank reserves, the balance sheet of the bank reads

$$
d_{t}=l_{t}
$$

The bank operates competitively in the market for labor and collateral, taking the collateral service yield of equity $c s y_{t}$ and the banking real wage rate, $w_{t}^{m}$, as given. Inserting equation (28) and the technological constraint (26) in the profit function (27), and taking the partial derivatives with respect to the input 
demands, $m_{t}$ and $v_{t}$, result in the following first order conditions for profit maximization

$$
\begin{aligned}
& \left(r_{t}^{l}-r_{t-1}^{d}\right) \frac{(1-a) m_{t}^{\chi-1} l_{t}}{a\left(e^{\varepsilon_{t}^{l}} v_{t}\right)^{\chi}+(1-a) m_{t}^{\chi}}-w_{t}^{m}=0 \\
& \left(r_{t}^{l}-r_{t-1}^{d}\right) \frac{a e^{\chi \varepsilon_{t}^{l}} v_{t}^{\chi-1} l_{t}}{a\left(e^{\varepsilon_{t}^{l}} v_{t}\right)^{\chi}+(1-a) m_{t}^{\chi}}-c s y_{t}=0
\end{aligned}
$$

The real interest rate on loans consistent with the banking labor demand equation $\left(m_{t}\right)$ is

$$
r_{t}^{l}=r_{t-1}^{d}+\frac{w_{t}^{m}}{\frac{(1-a) m_{t}^{\chi-1} l_{t}}{a\left(e^{\varepsilon_{t}^{l}} v_{t}\right)^{\chi}+(1-a) m_{t}^{\chi}}}
$$

which has two components:

- the real interest rate paid for the deposit used to produce the loan $\left(r_{t-1}^{d}\right)$, and

- the marginal cost of labor required to transform one unit of deposits in one unit of loans $\left(\frac{w_{t}^{m}}{\partial l_{t} / \partial m_{t}}\right)$.

The semi-loglinear approximation to (29) gives

$$
r_{t}^{l}-r^{l}=\left(r_{t-1}^{d}-r^{d}\right)+\left(r^{l}-r^{d}\right)\left(\widehat{w}_{t}^{m}-\widehat{l}_{t}+(1-\Omega \chi) \widehat{m}_{t}+\Omega \chi\left(\widehat{v}_{t}+\varepsilon_{t}^{l}\right)\right)
$$

where $\Omega=\frac{a v^{\chi}}{a v^{\chi}+(1-a) m^{\chi}}$ is the steady-state share of collateral (equity) in loan production. The financial accelerator mechanism can be reflected through the inverse relation between fluctuations of equity, $\widehat{v}_{t}$, and the cost of loans, $r_{t}^{l}$, obtained for values of $\chi<0$. The reaction of $r_{t}^{l}$ to a change in collateral is stronger when the steady-state spread, $r^{l}-r^{d}$, is higher; the steady-state share of collateral, $\Omega$, is higher; and the elasticity of substitution, $1 /(1-\chi)$, is lower. Regarding the last effect, a very high and negative $\chi$, which implies a very low elasticity of substitution, makes the effect of $\widehat{v}_{t}$ over $r_{t}^{l}$ huge. That might be considered a "real" rigidity for loan production in the sense discussed by Gopinath and Itskhoki (2010). Accordingly, we consider that a loan production technology is rigid (flexible) when it is characterized by a low (high) elasticity of substitution between its inputs. ${ }^{11}$

Based on the above first order conditions, the equilibrium return for the collateral service of equity turns out to be

$$
c s y_{t}=\left(r_{t}^{l}-r_{t-1}^{d}\right) \frac{l_{t}}{v_{t}} \frac{a\left(e^{\varepsilon_{t}^{l}} v_{t}\right)^{\chi}}{a\left(e^{\varepsilon_{t}^{l}} v_{t}\right)^{\chi}+(1-a) m_{t}^{\chi}}
$$

where plugging in expression (29) simplifies to

$$
\operatorname{cs} y_{t}=w_{t}^{m} \frac{a}{(1-a)}\left(\frac{m_{t}}{e^{\varepsilon_{t}^{l}} v_{t}}\right)^{1-\chi}
$$

\footnotetext{
${ }^{11}$ The optimal allocation of banking inputs implies $\frac{w_{t}^{m}}{c s y_{t}}=\frac{1-a}{a}\left(\frac{e^{\varepsilon_{t}^{l}} v_{t}}{m_{t}}\right)^{1-\chi}$, i.e. the standard microeconomic condition that equalizes the ratio of input prices to the ratio of their marginal products. Hence, a greater rigidity on banking can be captured by a lower value of the elasticity of substitution $(1-\chi)^{-1}$. Either a financial shock, $\varepsilon_{t}^{l}$, or a change in collateral, $v_{t}$, will have larger effects on the relative price of inputs, $\frac{w_{t}^{m}}{c s y_{t}}$, because of the loss of efficiency at factor substitutability.
} 
Finally, the (collateralized) external finance premium, efp , can be defined as the difference between the real interest rate on loans and the real returns collected by the households from the bank (which include both returns on deposits and equity). Formally, this implies

$$
e f p_{t}=r_{t}^{l}-r_{t-1}^{d}-\frac{c s y_{t} v_{t}}{l_{t}}=\left(r_{t}^{l}-r_{t-1}^{d}\right)\left(1-\frac{a\left(e^{\varepsilon_{t}^{l}} v_{t}\right)^{\chi}}{a\left(e^{e_{t}^{l}} v_{t}\right)^{\chi}+(1-a) m_{t}^{\chi}}\right)
$$

which in steady state becomes efp $=\left(r^{l}-r^{d}\right)(1-\Omega)$. The external finance premium actually represents the spread between the interest rate of collateralized loans $\left(r_{t}^{l}-\frac{c s y_{t} v_{t}}{l_{t}}\right)$ and the return obtained from providing deposits to the banks $\left(r_{t-1}^{d}\right) .{ }^{12}$ If no monitoring labor is required to produce them $(a=1)$, the external finance premium is equal to zero as the interest rate spread is totally compensated by the collateral service return, $r_{t}^{l}-r_{t-1}^{d}=\frac{c s y_{t} v_{t}}{l_{t}}$. In the opposite extreme case, if equity does not yield any collateral service for loan production $(a=0)$, the external finance premium coincides with the interest-rate spread.

\subsection{Central bank}

The central bank acts as a social planner who maximizes household's utility subject to the competitive equilibrium. Let us formally introduce the variable $l e i s_{t}=1-n_{t}-m_{t}$ as the amount of leisure time. In the tradition of Ramsey (1927), the bank chooses prices and quantities in competitive equilibrium in order to maximize intertemporal household utility. In particular, we follow Woodford (2003) to have the central bank in period $t$ maximizing the following quadratic approximation to household's intertemporal utility

$$
\mathcal{W}_{t}=\sum_{j=0}^{\infty} \beta^{j}\left(c^{1-\sigma}\left(\widehat{c}_{t+j}-\frac{(\sigma-1)}{2} \widehat{c}_{t+j}^{2}\right)+\Psi \text { leis }{ }^{1-\gamma}\left(\widehat{\operatorname{leis}}_{t+j}-\frac{(\gamma-1)}{2} \widehat{l e i s}_{t+j}^{2}\right)\right)
$$

subject to the set of constraints that describe the competitive equilibrium of the economy. Intuitively, the welfare function (33) indicates that the level of either consumption or leisure raises welfare whereas their square log deviations with respect to the steady state levels reduce welfare. The central bank is committed to preserve the optimal monetary policy in the future. Particularly, we follow the "timeless perspective" approach described in Woodford (1999, page 18). Monetary policy is decided as a plan that should be preserved in any present, current or future period. This implies that the equations that describe the state of the economy must be considered as constraints for any period. The result is a targeting rule under commitment which outperforms the targeting rule under discretion (Svensson and Woodford, 2005; Giannoni and Woodford, 2005). Hence, the set of equations describing the dynamics of the economy, which the central bank takes as constraints in the optimizing program, are considered at any $t+j$ period for $j=\ldots,-2,-1,0,1,2, \ldots$ The law of iterated expectations is used in the optimal control exercise.

\footnotetext{
${ }^{12}$ This notion of the external finance premium is consistent with models featuring financial frictions a la Bernanke and Gertler (1989) where higher net worth (collateral) reduces agency costs and the external finance premium is lower.
} 
Due to its space requirements, Section 7 of the Appendix describes the optimal control exercise of the central bank. The targeting rule comprises 31 equations that may provide solution paths for the 16 endogenous variables listed above plus the 15 Lagrange multipliers of the competitive-equilibrium constraints.

\subsection{Overall resources constraint}

Using the cost of borrowing, $r_{t}^{l} l_{t}^{h}=r_{t}^{l} \tau_{h}\left(c_{t}+I\left(\frac{k_{t+1}}{k_{t}}\right) k_{t}\right)$, the zero-profit condition for the competitive bank, $\left(r_{t}^{l}-r_{t-1}^{d}\right) l_{t}=w_{t}^{m} m_{t}+c s y_{t} v_{t}$, and the equilibrium condition for banking labor, $m_{t}^{s}=m_{t}$, in the household budget constraint (3), we obtain

$$
\begin{aligned}
& \frac{w_{t} n_{t}^{s}}{1+u_{t}}+r_{t}^{k} k_{t}+x_{t} e_{t}+r_{t-1}^{d} d_{t}+\left(r_{t}^{l}-r_{t-1}^{d}\right) l_{t}+c s y_{t} v_{t}\left(x_{t}-1\right)= \\
&\left(1+\tau_{h} r_{t}^{l}\right) c_{t}+\left(1+\tau_{h} r_{t}^{l}\right) I\left(\frac{k_{t+1}}{k_{t}}\right) k_{t}+\left(x_{t+1}-x_{t}\right) v_{t}+\left(d_{t+1}-d_{t}\right)
\end{aligned}
$$

Next, the introduction of the portfolio investment equilibrium conditions, $x_{t}=1$ and $x_{t+1}=1$, together with the bank balance sheet $\left(l_{t}=d_{t}\right)$ yield

$$
\frac{w_{t} n_{t}^{s}}{1+u_{t}}+r_{t}^{k} k_{t}+e_{t}+r_{t}^{l} l_{t}=\left(1+\tau_{h} r_{t}^{l}\right) c_{t}+\left(1+\tau_{h} r_{t}^{l}\right) I\left(\frac{k_{t+1}}{k_{t}}\right) k_{t}+\left(d_{t+1}-d_{t}\right)
$$

Since the definition of the rate of unemployment is

$$
u_{t}=\frac{n_{t}^{s}}{n_{t}}-1
$$

this implies that $n_{t}^{s}=\left(1+u_{t}\right) n_{t}$, and the household budget constraint in terms of effective labor income becomes

$$
w_{t} n_{t}+r_{t}^{k} k_{t}+e_{t}+r_{t}^{l} l_{t}=\left(1+\tau_{h} r_{t}^{l}\right) c_{t}+\left(1+\tau_{h} r_{t}^{l}\right) I\left(\frac{k_{t+1}}{k_{t}}\right) k_{t}+\left(d_{t+1}-d_{t}\right)
$$

Meanwhile, aggregate real earnings are

$$
\begin{aligned}
e_{t} & =\int_{0}^{1} e_{t}(\omega) d \omega=\frac{1}{P_{t}} \int_{0}^{1} P_{t}(\omega) y_{t}(\omega) d \omega-\frac{1}{P_{t}} \int_{0}^{1} W_{t}(\omega) n_{t}(\omega) d \omega-r_{t}^{k} \int_{0}^{1} k_{t}(\omega) d \omega-r_{t}^{l} \int_{0}^{1} l_{t}(\omega) d \omega \\
& =y_{t}-w_{t} n_{t}-r_{t}^{k} k_{t}-r_{t}^{l} l_{t}
\end{aligned}
$$

with real aggregate output, $y_{t}=\frac{1}{P_{t}} \int_{0}^{1} P_{t}(\omega) y_{t}(\omega) d \omega$, real aggregate labor costs, $w_{t} n_{t}=\frac{1}{P_{t}} \int_{0}^{1} W_{t}(\omega) n_{t}(\omega) d \omega$, real aggregate capital rental cost, $r_{t}^{k} k_{t}=r_{t}^{k} \int_{0}^{1} k_{t}(\omega) d \omega$, and real aggregate loans, $l_{t}=\int_{0}^{1} l_{t}(\omega) d \omega$. Inserting real aggregate earnings, $e_{t}=y_{t}-w_{t} n_{t}-r_{t}^{k} k_{t}-r_{t}^{l} l_{t}$, in the income-expenditures expression, we get

$$
y_{t}=\left(1+\tau_{h} r_{t}^{l}\right) c_{t}+\left(1+\tau_{h} r_{t}^{l}\right) I\left(\frac{k_{t+1}}{k_{t}}\right) k_{t}+\left(d_{t+1}-d_{t}\right)
$$

The uses of output are consumption, capital accumulation, and net increase in deposits. Recalling the steady-state properties of the investment function, and since the change in deposits is zero in steady state, the loglinearized overall resources constraint determines log-fluctuations of output as a weighted average 
between log-fluctuations of consumption and log-fluctuations of investment spending, augmented with the cost of the external finance, $\left(r_{t}^{l}-r^{l}\right)$ :

$$
\widehat{y}_{t}=\frac{\left(1+\tau_{h} r^{l}\right) c}{y} \widehat{c}_{t}+\frac{\left(1+\tau_{h} r^{l}\right) \delta k}{y}\left(\frac{1}{\delta} \widehat{k}_{t+1}-\frac{(1-\delta)}{\delta} \widehat{k}_{t}\right)+\tau_{h}\left(r_{t}^{l}-r^{l}\right)
$$

The equilibrium conditions in the goods market, asset markets and labor markets are discussed in Section 4 of the Appendix. As a summary of the model, both the steady-state non-linear system of equations and the complete set of log-linearized dynamic equations are respectively displayed in Sections 5 and 6 of the Appendix.

\section{Calibration}

Table 1 describes the baseline calibration of the model for quarterly periods. The intertemporal discount factor is set at $\beta=0.995$, obtained from a rate of intertemporal preference $\rho=0.005$ that implies a $2 \%$ annualized steady-state real rate of return for deposits. The utility function is set with a consumption elasticity of marginal utility at $\sigma=1.5$, in line with the empirical estimates of the US and the Euro Area economies (Smets and Wouters, 2003 and 2007). The parameter that measures the weight of leisure in the utility function takes the value $\Psi=0.48$, which implies that $1 / 3$ of total time is spent at work in the steady-state solution of the model, $n+m=\frac{1}{3}$. The leisure curvature parameter is calibrated to induce a low labor supply Frisch elasticity as found in most empirical evidence (Altonji, 1986; Pencavel, 1986; and Domeij and Flodén, 2006). We set $\gamma=4$ so that labor supply elasticity, $\frac{1}{\gamma} \frac{1-(n+m)}{n}$, turns out to be slightly below 0.5 .

The elasticity of the stock of capital in the production of goods is $\alpha=0.3$, which results in the steady-state income shares of $54 \%$ for labor, $23 \%$ for capital and $23 \%$ for equity. The rate of capital depreciation is fixed at $\delta=0.025$ in order to imply an annualized depreciation rate of $10 \%$. The elasticity of the adjustment cost function, $\epsilon$, is set at a value that provides a volatility of investment (measured by its standard deviation) that is three times higher than the one of consumption, as observed in the US (Casares et al., 2014). This leads to assign a value of $\epsilon=4.5$. The elasticity of substitution across consumption goods is $\theta_{p}=10$, and the elasticity of substitution across labor services is $\theta_{w}=4$, which jointly imply a $29 \%$ mark-up in steady state. ${ }^{13}$ Price and wage rigidities are introduced with the same Calvo-type probability $\eta=0.75$ to have the average frequency of optimal setting at one time per year, as suggested by Taylor (1999a) and commonly assumed in the New Keynesian literature.

The parameters that govern the financial aspects of the model are calibrated using data from the Great Moderation period that runs from 1984:1 to 2007:4 (usually referred as normal times). ${ }^{14}$ The coefficients

\footnotetext{
${ }^{13}$ The optimality condition for pricing, equation (19), leads to a mark-up in steady state equal to: $\frac{\theta_{p}}{\theta_{p}-1}\left(1+\frac{1-\alpha}{\alpha+\theta_{w}}\right)-1$.

${ }^{14}$ Our US data source is the FRED database released by the Federal Reserve Bank of St. Louis, except for the series of the interest-rate spreads that is taken from the website of the Board of Governors of the Federal Reserve System.
} 
that determine the borrowing requirements for firms and households are assigned at the values that provide a good matching to the average of the stock of loans relative to GDP found in the US. For household loans, $l_{t}^{h}$, we use the series of Consumer Loans and for firm loans, $l_{t}^{f}$, we consider the series of Commercial and Industrial Loans. We match the steady-state ratios in the model, $l^{h} / y$ and $l^{f} / y$, to the average of real loans to quarterly real GDP observed in the US during the Great Moderation that are, respectively, $l^{h} / y=0.23$ and $l^{f} / y=0.38$. To accomplish this matching, the required values used in the baseline calibration are $\tau_{h}=0.24$ and $\tau_{f}=0.51$.

Table 1. Baseline calibration.

\begin{tabular}{lc}
\hline \hline \multicolumn{1}{c}{ Parameter description } & Value \\
$\beta$, intertemporal discount factor & 0.995 \\
$\sigma$, elasticity of consumption marg. utility & 1.50 \\
$\gamma$, elasticity of leisure marg. utility & 4.00 \\
$\Psi$, leisure weight in total utility & 0.48 \\
$\alpha$, capital share in goods production & 0.30 \\
$\delta$, rate of capital depreciation & 0.025 \\
$\epsilon$, capital adjustment costs elasticity & 4.5 \\
$\chi$, curvature in loan production & 0.0 \\
$a$, collateral weight in loan production & 0.65 \\
$B$, scale parameter in loan production & 0.66 \\
$\tau_{f}$, firm external finance & 0.24 \\
$\tau_{h}$, household external finance & 0.51 \\
$\theta_{p}$, Dixit-Stiglitz demand elasticity & 10.0 \\
$\theta_{w}$, Dixit-Stiglitz labor supply elasticity & 4.0 \\
$\eta$, probability of price/wage rigidity & 0.75 \\
\hline
\end{tabular}

In the baseline calibration of the CES loan production technology (26), the elasticity parameter, $\chi$, is parameterized at the Cobb-Douglas case $(\chi=0.0)$ in order to provide a unit elasticity of substitution between collateral and labor, $(1-\chi)^{-1}=1$, commonly assumed in the related literature. This elasticity parameter will be modified later in order to examine monetary policy under deeper banking rigidities. Following Goodfriend and McCallum (2007), we set $a=0.65$ in order to obtain a $65 \%$ collateral share for loan production in steady state. The scale parameter of loan production, $B$, is fixed at the value that results in a steady-state external finance premium $e f p=0.01$, i.e. $4 \%$ in annualized terms. Such value coincides with the sample average of the series Commercial and Industrial Loan Rates Spreads over intended Federal Funds Rate, available for the period 1986:3-2007:4, which requires setting $B=0.66 .{ }^{15}$ The size of the

\footnotetext{
${ }^{15}$ We looked at the series of loans of size "Less than $\$ 100,000 "$ to represent the case of short-run collateralized lending (one quarter duration) that is assumed in the model. The average interest-rate spread is $4 \%$. For larger loans the spread is lower.
} 
banking sector that results in the model is consistent with empirical evidence: the steady-state ratio of banking labor over total labor is $\frac{m}{n}=0.0115(1.15 \%)$ in the model, whereas in the US data the average ratio of Employees in Commercial Banking over Total Nonfarm Payroll during the Great Moderation period was very close to $1 \%$.

The parameters that characterize the exogenous shocks are calibrated to match both the volatility and the persistence of the quarterly series of fluctuations of US real GDP, inflation and the interest-rate spread during the available sample period 1986:3-2007:4. The indicator of cyclical fluctuations of output, $\widehat{y}_{t}$, has been obtained by filtering the log of the US Real GDP with a linear trend. The rate of inflation is the rate of growth of the GDP Implicit Price Deflator of the US economy, and the interest-rate spread is measured by the series of external finance premium mentioned above. The model has been simulated for 106 observations and the first 20 were discarded to guarantee a random start (which might be different from the steady state) and the same number of observations as in the time series of the actual data. The simulations were repeated 10,000 times and average values of standard deviations and coefficients of autocorrelation were computed. We have selected the coefficients of autocorrelation of the AR(1) shocks and the standard deviation of their innovations to provide a good empirical fit to the US second-moment statistics. Table 2 collects the values set and the comparison between the autocorrelation and volatilities of output fluctuations, inflation and the interest-rate spread generated by the model and in the data.

Table 2. Calibration and empirical fit

\begin{tabular}{lcc}
\hline \hline Calibration of the $\operatorname{AR}(1)$ shocks: & & \\
& Autocorrelation & Standard deviation, \% \\
\cline { 2 - 3 } Technology shocks & 0.96 & 0.69 \\
Price-push shocks & 0.60 & 0.18 \\
Financial shocks & 0.97 & 1.79 \\
\hline
\end{tabular}

Statistics of persistence and volatility:

\begin{tabular}{lcccc} 
& \multicolumn{2}{c}{ Autocorrelation } & \multicolumn{2}{c}{ Standard deviation, \% } \\
\cline { 2 - 5 }$\widehat{y} \hat{y}, \log$ fluctuations of real GDP & 0.95 & 0.93 & 1.68 & 1.68 \\
$4 \pi$, rate of inflation (ann.) & 0.61 & 0.62 & 0.91 & 0.91 \\
$4 e f p$, interest-rate spread (ann.) & 0.93 & 0.92 & 0.39 & 0.39 \\
\hline
\end{tabular}

\section{Monetary policy analysis}

In order to understand the interactions between monetary policy, banking, and financial shocks, the stabilizing performance of monetary policy rules is examined under the baseline calibration in comparison with three alternative scenarios:

i) High banking rigidities, introduced by setting a low elasticity of substitution at loan production. The 
baseline calibration $(\chi=0)$ implies a unit elasticity of substitution, $(1-\chi)^{-1}=1$. For a more rigid loan production technology, we set $\chi=-9$ which results in a much lower elasticity of substitution for collateral $(1-(-9))^{-1}=0.1 .^{16}$ We recall that a lower elasticity of substitution of inputs means a less efficient technology because the input substitution along an isoquant (keeping production constant) is more costly.

ii) Financial business cycle, i.e. aggregate fluctuations driven exclusively by financial shocks. Thus, the other exogenous sources of variability (technology shocks and price-push shocks) are shut down by setting their standard deviations at $0.0\left(\sigma_{z}=\sigma_{p}=0\right)$.

iii) High banking rigidities under financial business cycle obtained by simultaneously setting $(1-\chi)^{-1}=$ 0.1 and $\sigma_{z}=\sigma_{p}=0$.

The monetary policy of the baseline model is the Ramsey-type targeting rule described in Subsection 2.4. However, the central bank may not be able to implement such targeting rule because of the following practical reasons. First, some of the variables of the rule are not observable (for example, the exogenous shocks). Second, the targeting rule itself comprises one set of 31 equations (displayed in Section 7 of the Appendix) that must hold simultaneously, involving rational expectations and exogenous sources of variability. Processing all that information would be a colossal work for the central bank. Third, central banks usually announce monetary policy actions through changes in the nominal interest rate for interbank borrowing. Based on these arguments, and on the problems of lack of robustness to model changes found in targeting rules (Levin and Williams, 2003), we also take the instrumental rule approach (McCallum, 1988; Taylor, 1999b) to propose an interest-rate rule that would set the nominal interest rate of deposits in a way that best mimicks the prescription of the targeting rule. ${ }^{17}$ The variables that the central bank responds to are now both observable and relevant: the rate of inflation (most central banks of modern economies follow inflation targeting policies), the rate of unemployment (central banks also tend to look carefully at developments in the labor market) and the external finance premium as an indicator of the financial tightness observed in the banking sector. ${ }^{18}$ Formally, such instrument rule can be written as follows

$$
R_{t}-R=\mu_{\pi}\left(\pi_{t}-\pi\right)+\mu_{u} u_{t}+\mu_{e f p}\left(e f p_{t}-e f p\right)+\varepsilon_{t}^{R}
$$

where the sign of the policy coefficients are conjectured to be $\mu_{\pi}>0, \mu_{u}<0$, and $\mu_{\text {efp }}<0$. The exogenous component, $\varepsilon_{t}^{R}$, brings the non-systematic policy actions, which may include the errors in replicating the optimal policy.

The optimized coefficients of the instrument rule (35) have been estimated from simulations of the model with the optimal monetary policy (targeting rule). As assumed in the calibration, every model simulation

\footnotetext{
${ }^{16}$ The weight coefficient of the loan production technology, $a$, has been reset to keep the collateral share in steady-state, $\Omega$, unchanged at $65 \%$.

${ }^{17}$ The model abstracts from interbank lending and borrowing. The interest rate of deposits represents the referential rate of return for any risk-free one period asset.

${ }^{18}$ Unconventional monetary policies might be desirable in the presence of financial frictions as discussed in Cúrdia and Woodford (2010).
} 
contains 106 observations and the first 20 are dropped. With the 86 remaining observations, we run an Ordinary Least Squares (OLS) regression of (35) and store the estimates of the policy coefficients $\mu_{\pi}, \mu_{u}$ and $\mu_{e f p}$, as well as the series of residuals. We repeat the simulation exercise and the OLS estimation for 10,000 times and compute the average and standard deviation of the estimated policy coefficients. Table 3 collects the mean and standard deviation of the estimates in the four alternative scenarios mentioned above

Table 3. Optimized monetary policy coefficients for the instrument rule (35).

\begin{tabular}{rcccccc}
\hline \hline & \multicolumn{3}{c}{ Systematic } & \multicolumn{3}{c}{ Residuals } \\
& & $\mu_{\pi}$ & $\mu_{u}$ & $\mu_{\text {efp }}$ & $\rho_{\varepsilon^{R}}$ & $\sigma_{\varkappa^{R}}, \%$ \\
\cline { 2 - 7 } Baseline calibration & & & & & \\
& Mean & 0.59 & -0.10 & 0.03 & 0.74 & 0.0233 \\
Standard deviation & $(0.02)$ & $(0.01)$ & $(0.04)$ & $(0.07)$ & $(0.0022)$
\end{tabular}

High banking rigidities

$\begin{array}{rccccc}\text { Mean } & 0.63 & -0.08 & -0.16 & 0.72 & 0.0258 \\ \text { Standard deviation } & (0.02) & (0.01) & (0.07) & (0.07) & (0.0027)\end{array}$

Financial business cycle

$\begin{array}{rccccc}\text { Mean } & 1.57 & -0.34 & -0.26 & 0.06 & 0.0022 \\ \text { Standard deviation } & (0.06) & (0.02) & (0.02) & (0.11) & (0.00021)\end{array}$

High banking rigidities and financial business cycle

\begin{tabular}{rccccc} 
Mean & 1.86 & -0.37 & -3.89 & 0.59 & 0.0119 \\
Standard deviation & $(0.19)$ & $(0.05)$ & $(0.61)$ & $(0.08)$ & $(0.0024)$ \\
\hline
\end{tabular}

In the baseline calibration, the implementation of the optimal (Ramsey-type) rule brings significant reactions of the nominal interest rate to inflation deviations $\left(\mu_{\pi}=0.59\right)$ and to the rate of unemployment $\left(\mu_{u}=-0.10\right)$. The signs of the central-bank responses are the ones expected for the goal of stabilizing aggregate fluctuations in the goods and labor markets. However, the optimized response to the external finance premium is slightly positive $\left(\mu_{e f p}=0.03\right)$, though not statistically significant because the standard deviation of the estimate is 0.04 (accepting the null hypothesis of having $\mu_{e f p}=0.0$ in the Student's t-test). Thus, in the baseline calibration of the model the central bank should not pay any significant attention to the changes in the external finance premium. This result changes under alternative calibrations as we show below.

Some of the variability of the nominal interest rate under the optimal rule cannot be captured by the systematic part of the instrument rule (35) and goes in the error term, $\varepsilon_{t}^{R}$. Its generating process can 
also be estimated from the residuals of the simulations. We test the $\operatorname{AR}(1)$ model, $\varepsilon_{t}^{R}=\rho_{\varepsilon^{R}} \varepsilon_{t-1}^{R}+\varkappa_{t}^{R}$, where $\left|\rho_{\varepsilon^{R}}\right|<1$ is the coefficient of autocorrelation and the innovation $\varkappa_{t}^{R}$ is white noise with a constant standard deviation, $\sigma_{\varkappa^{R}}$. Both $\rho_{\varepsilon^{R}}$ and $\sigma_{\varkappa^{R}}$ have been estimated as the average values obtained from running OLS regressions of the the 10,000 simulated series of residuals. As Table 3 displays, the residuals are moderately autocorrelated $\left(\rho_{\varepsilon^{R}}=0.74\right)$ and their innovations have a low standard deviation $\left(\sigma_{\varkappa^{R}}=\right.$ $0.0233 \%$ ). These monetary shocks are the result of not being able to completely replicate the optimal rule using the instrument rule (35).

When banking rigidities are high (low elasticity of substitution for the inputs of loan production, $\left.(1-\chi)^{-1}=0.1\right)$, the optimal policy reaction constrained to (35) results in a slightly stronger response to inflation deviations and a slightly milder one to the rate of unemployment (compare numbers in Table 3). The impact of banking rigidities on the optimized instrumental policy is really important for the coefficient of reactions to the external finance premium. This turns around from being virtually none to having a negative value $\left(\mu_{e f p}=-0.16\right)$ with a standard deviation of the estimate at 0.07 . There is an intuitive interpretation of this finding: since high banking rigidities amplify the financial accelerator effects, the central bank should take a more aggressive stand on controlling its fluctuations. If the external finance premium rises, the optimal policy recommends a expansionary monetary policy (lower interest rates) to stimulate demand and overcome the contractionary effects of higher cost of borrowing. Let us recall that the Ramsey-type optimal policy derived in our model is aimed at minimizing the volatilities of both consumption and leisure, which require stability in both the goods and labor markets, respectively.

Targeting rules are model specific. Furthermore, they must rely on a particular model calibration. Our baseline calibration is meant to illustrate mild business cycles (as viewed in the Great Moderation period). Would the optimal policy rule change if business cycles were not conventional? In particular, what would optimal monetary policy be like in a business cycle driven by financial shocks? We have investigated these questions by recalibrating the model with only financial shocks. Such scenario is designed shutting down both technology and price-push shocks $\left(\sigma_{z}=\sigma_{p}=0\right)$, and raising the standard deviation of financial shocks by 10 times the value initially assumed $\left(10 \sigma_{l}\right)$. We have solved the model with the welfare-theoretic targeting rule and then we have approximated that optimal policy with the OLS-estimated instrument rule (35). As Table 4 shows, the policy prescriptions change dramatically relative to the baseline calibration. The central bank should be much more aggressive in the interest-rate responses to both the rate of inflation $\left(\mu_{\pi}=1.57\right)$ and the rate of unemployment $\left(\mu_{u}=-0.34\right)$ than in the case of business cycles driven by the three shocks. The reaction to the external finance premium is also stronger $\left(\mu_{\text {efp }}=-0.26\right)$.

Finally, we have also examined the banking sector with low elasticity of substitution and financial shocks. The estimated policy coefficients consistent with the optimal rule are slightly higher than in the case with unit elasticity. However, the intervention to stabilize the spread turns much deeper $\left(\mu_{e f p}=-3.89\right)$ to refrain the need of controlling the impact of the financial accelerator on consumption and leisure variability.

Next, we carry out some analysis of the impulse-response functions and the volatilities of the variables 
under the baseline calibration and the three alternative scenarios mentioned above. In addition, we have computed the unconditional expectation of the central-bank objective function to measure the welfare level attained. For comparative purposes, the performance of the Taylor (1993) rule is also going to be examined, as a well-known prescription for macroeconomic stability with an instrument rule over normal times such as the Great Moderation. Taking Taylor (1993)'s original coefficients for the responses of the nominal interest rate to inflation deviations and for the responses to fluctuations of output, we have ${ }^{19}$

$$
R_{t}-R=1.5\left(\pi_{t}-\pi\right)+\frac{0.5}{4} \widehat{y}_{t}
$$

Table 4 provides the standard deviations of key variables and the welfare level.

Table 4. Stabilizing performance of monetary policy rules.

\begin{tabular}{|c|c|c|c|c|c|c|c|c|c|}
\hline \multirow{3}{*}{ Baseline calibration } & \multicolumn{8}{|c|}{ Standard deviations, \% } & \multirow{2}{*}{$\begin{array}{c}\text { Welfare } \\
10^{6} E[\mathcal{W}]\end{array}$} \\
\hline & \multirow[t]{2}{*}{$\widehat{y}$} & \multirow[t]{2}{*}{$u$} & \multirow[t]{2}{*}{$4 R$} & \multirow[t]{2}{*}{$4 \pi$} & \multirow[t]{2}{*}{$\widehat{v}$} & \multirow[t]{2}{*}{$4 e f p$} & \multirow[t]{2}{*}{$\widehat{c}$} & \multirow[t]{2}{*}{$\widehat{l e i s}$} & \\
\hline & & & & & & & & & \\
\hline Optimal rule & 1.68 & 0.41 & 0.64 & 0.91 & 1.60 & 0.39 & 1.17 & 0.24 & -66.15 \\
\hline Optimized instrument rule (35) & 1.37 & 0.81 & 0.92 & 1.15 & 1.28 & 0.38 & 0.92 & 0.49 & -94.42 \\
\hline Taylor rule & 1.20 & 1.40 & 1.49 & 1.39 & 0.99 & 0.38 & 0.71 & 0.79 & -183.59 \\
\hline \multicolumn{10}{|l|}{ High banking rigidities } \\
\hline Optimal rule & 1.62 & 0.76 & 0.87 & 1.16 & 1.49 & 0.33 & 1.29 & 0.33 & -90.65 \\
\hline Optimized instrument rule (35) & 1.14 & 1.30 & 1.30 & 1.56 & 1.26 & 0.32 & 0.87 & 0.66 & -146.97 \\
\hline Taylor rule & 1.42 & 1.49 & 1.62 & 1.54 & 1.03 & 0.36 & 1.14 & 0.83 & -230.66 \\
\hline \multicolumn{10}{|l|}{ Financial business cycle } \\
\hline Optimal rule & 0.21 & 0.13 & 0.11 & 0.16 & 0.17 & 1.18 & 0.30 & 0.07 & -4.62 \\
\hline Optimized instrument rule $(35)$ & 0.21 & 0.13 & 0.11 & 0.16 & 0.17 & 1.18 & 0.30 & 0.07 & -4.74 \\
\hline Taylor rule & 0.28 & 0.18 & 0.24 & 0.25 & 0.11 & 1.19 & 0.32 & 0.10 & -6.38 \\
\hline \multicolumn{10}{|c|}{ High banking rigidities and financial business cycle } \\
\hline Optimal rule & 0.40 & 1.48 & 1.25 & 1.65 & 2.79 & 0.98 & 1.28 & 0.37 & -98.44 \\
\hline Optimized instrument rule (35) & 0.42 & 1.47 & 1.28 & 1.68 & 2.82 & 1.00 & 1.32 & 0.36 & -100.12 \\
\hline Taylor rule & 1.82 & 1.50 & 1.42 & 1.54 & 1.54 & 1.10 & 2.45 & 1.03 & -490.93 \\
\hline
\end{tabular}

Let us further discuss the results looking at the graphical analysis of impulse-response functions for the three different shocks included in the model: technology shock, inflation shock and financial shock.

\footnotetext{
${ }^{19}$ The reader may notice that the response coefficient to output fluctuations comes in divided by 4 . This transformation is made because Taylor (1993) estimates a policy rule where the interest rate was expressed in annualized rates of return and our model has been calibrated for quarterly observations.
} 


\subsection{Technology shock}

Figure 1 shows the impulse-response functions obtained from a technology shock of size equivalent to one standard deviation. Responses are compared across the alternative monetary policy rules and the level of banking rigidities. Remarkably, the implementation of the optimal targeting rule leads to the largest reactions on output and consumption, amplifying the expansionary effects of the technology shock in the goods market, relative to the action observed with the Taylor rule. By contrast, both unemployment and leisure get more stabilized with the optimal monetary policy than with the Taylor rule, which indicates that the labor market effects are dampened. It could be said that the optimal monetary policy is aimed at restoring the flexible-wage scenario. Although it is not shown in Figure 1, the rise of wage inflation with the optimal rule is nearly twice the one observed with the Taylor rule. Equity, the external finance premium and inflation have similar responses under the three rules. Also under the three rules, the financial accelerator works as firm equity rises and the countercyclical external finance premium stimulates demand (both consumption and investment increase with lower cost of borrowing) and reduces the real marginal cost. The nominal interest rate under the optimal rule falls at a lower extent than the Taylor rule prescription.

If loan production is subject to real rigidities (see right-side cells of Figure 1), the optimal rule has some additional difficulties on stabilizing consumption and leisure. In turn, the level of social welfare is lower with banking rigidities. Table 4 shows higher standard deviations of the two targeted variables (consumption and investment) in the model calibration with low banking elasticity, $(1-\chi)^{-1}=0.1$, compared to the baseline calibration. Under the optimal policy, the standard deviation of consumption increases from $1.17 \%$ to $1.29 \%$ and the standard deviation of leisure from $0.24 \%$ to $0.33 \%$. In turn, social welfare with banking rigidities falls by approximately $37 \%$ (from -66.15 to -90.65 ). ${ }^{20}$

Finally, the optimized instrument rule (35) does a better job approximating the targeting rule in the model without severe banking rigidities (baseline calibration). The low elasticity of substitution pushes the financial accelerator mechanism and the central bank must react to the external finance premium. As can be viewed in Figure 1, the dashed lines (optimized instrument rule) are more separated from the solid lines (targeting rules) in the case of banking rigidities. The welfare loss from applying the optimized instrument rule is found higher with banking rigidities than in the baseline calibration according to the numbers reported in Table 4.

\subsection{Inflation shock}

Figure 2 shows the effects of a price-push shock of size equivalent to its calibrated standard deviation. The targeting rule nearly achieves full stabilization as the responses of output, consumption, leisure and the

\footnotetext{
${ }^{20}$ It should be noticed that Table 4 reports the welfare levels in one million times actual units, due to the small numbers delivered as actual units.
} 

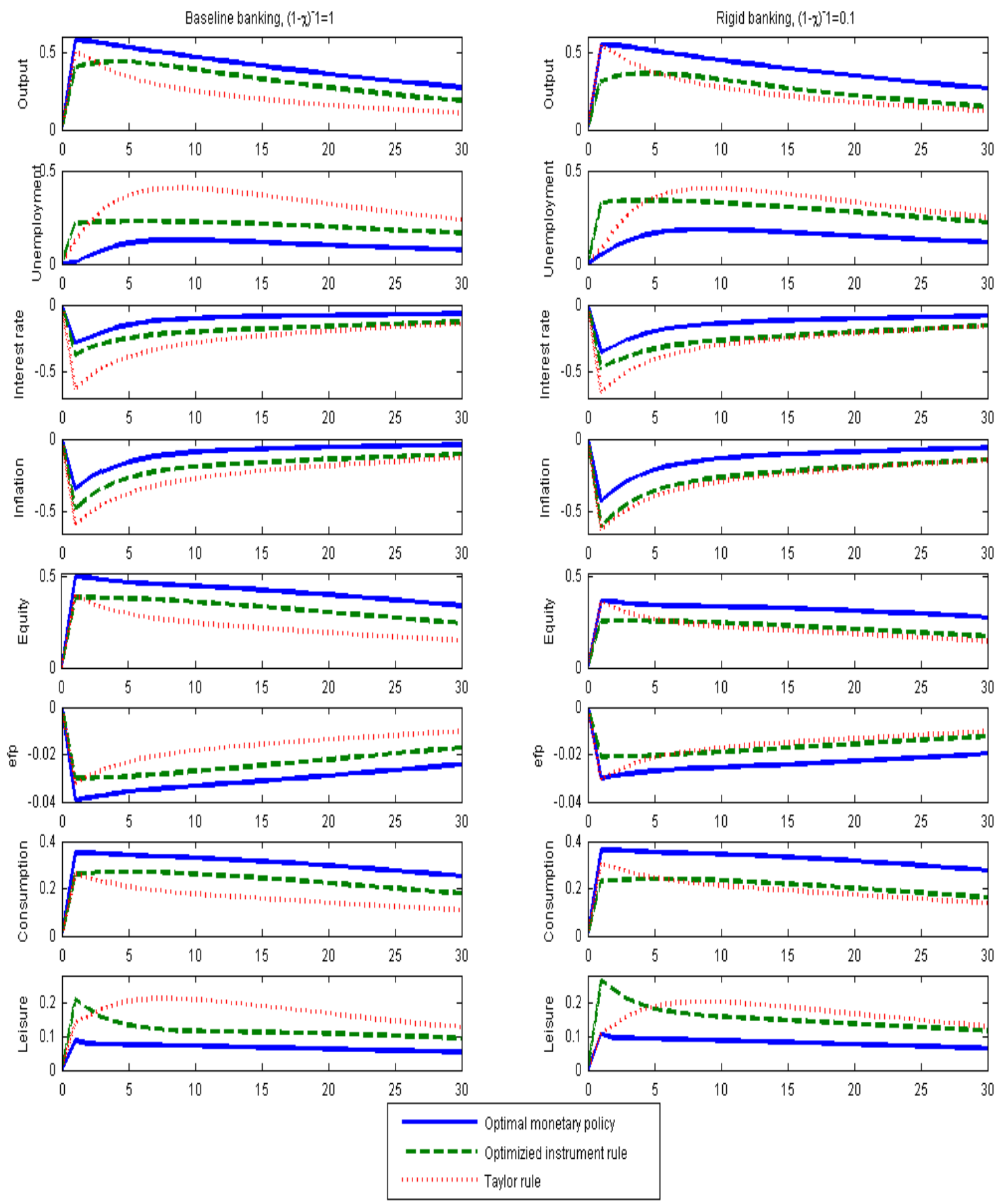

Figure 1: Technology shock. Impulse-response functions under alternative monetary policy rules and banking rigidity. 

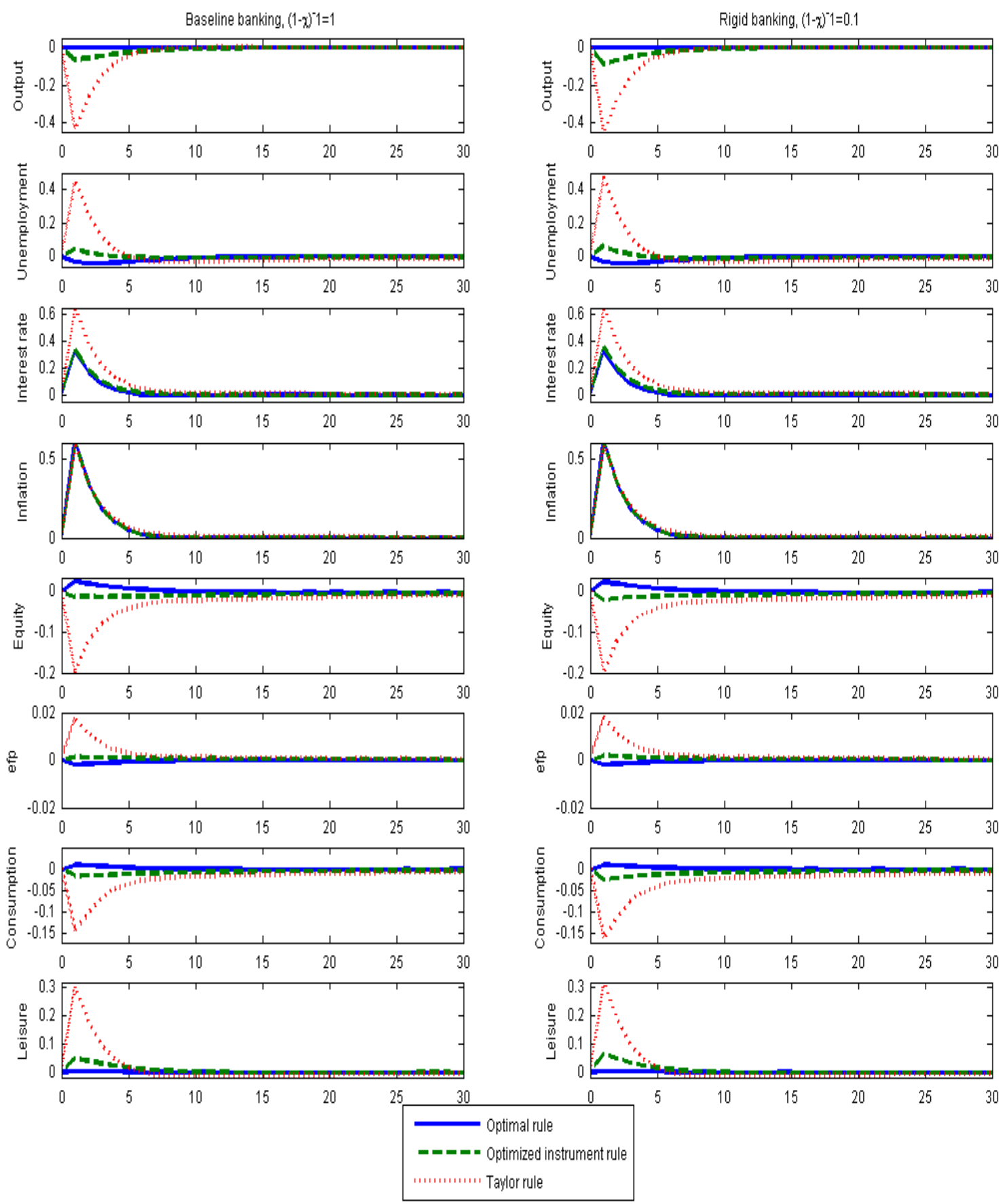

Figure 2: Inflation shock. Impulse-response functions under alternative monetary policy rules and banking rigidity. 
rate of unemployment are virtually flat. This desirable result is obtained with a moderate increase in the nominal interest rate at the time of the inflation hike (around half of the size of the increase obtained with a Taylor rule). Subsequently, the contributions of the inflation shock to the overall variability of output, unemployment, equity, the external finance premium, consumption and leisure are very small under the targeting rule. As commented above, technology shocks would explain most of the volatility of these variables. The optimized instrument rule (35), displayed with dashed lines in Figure 2 brings a small decline of output and consumption and a slight increase of unemployment. This economic contraction is quantitatively much larger if the Taylor rule is in place (dotted lines). Either the targeting rule or the optimized instrument rule provide crucial monetary policy reactions to stabilize the economy after an inflationary shock.

So, the implementation of the targeting rule recommends a small increase in the nominal interest rate that keeps the real interest rate unchanged in the presence of an inflation shock. With no significant change in the real interest rate, both consumption and investment will not fall and the economic recession does not develop. In the labor market, the rate of unemployment rises by more than $0.4 \%$ with the Taylor rule, whereas it barely changes if the targeting rule is implemented (actually, it goes slightly down because labor supply falls due to welfare effects). The model with the optimized instrument rule displays a slight increase of unemployment. Leisure time rises as a consequence of less effective labor employed. In terms of welfare, the optimal rule provides a much higher value than the Taylor rule because both consumption and leisure would be stabilized around their steady state levels and their square deviations around them are really small. The inflation shock mostly explains why the Taylor rule performs so poorly for macroeconomic stabilization and for attaining social welfare (numbers reported in Table 4).

The case with banking rigidities is almost indistinguishable from the baseline calibration. Looking at Figure 2, it could be said the responses of output, consumption, unemployment and leisure are slightly deeper (a few basis points) on the right-side plots compared to the left-side plots. The effects of the inflation shock on either the external finance premium or the cost of borrowing are small and the consequences of having more or less banking rigidities are not significant.

\subsection{Financial shock}

Finally, in Figure 3 we can see the responses to a shock of size equivalent to one standard deviation, which brings an exogenous increase in the effective amount of collateral for loan production. Both the choice of a monetary policy rule and the extent of banking rigidities play a key role on shaping the responses of macroeconomic variables. Regarding the latter, if banking rigidities are high, the quantitative implications of the financial shock are substantially greater. This finding is robust to any monetary policy setting. Thus, the effects of the financial shock are between five and ten times larger on unemployment, consumption and leisure with a lower banking elasticity (right-side plots of Figure 3) than in the baseline calibration (left-side 

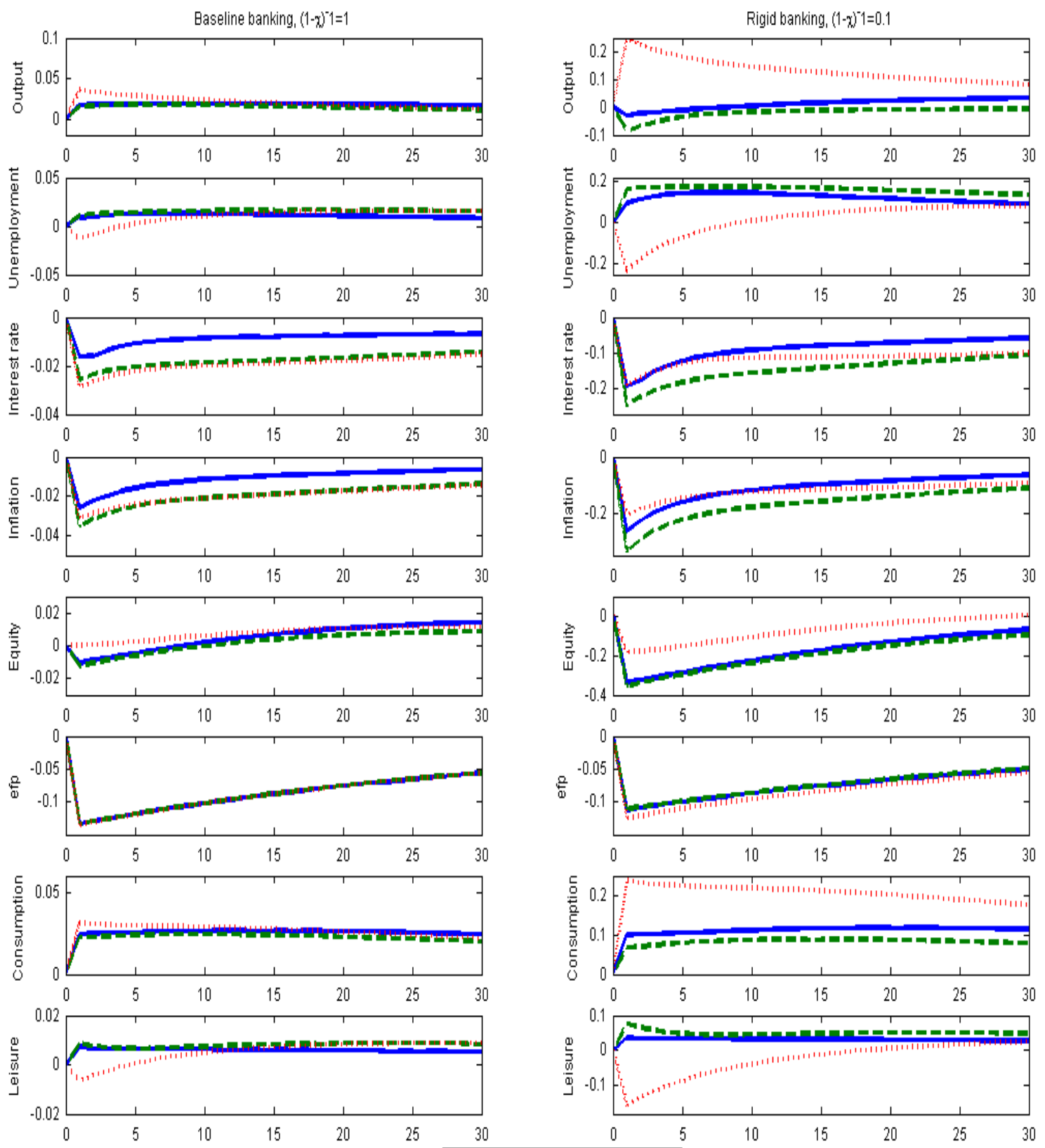

Optimal rule

-ーーー- Optimized instrument rule

Taylor rule

Figure 3: Financial shock. Impulse-response functions under alternative monetary policy rules and banking rigidity. 
plots of Figure 3). Having the optimal monetary policy combined with banking rigidities switches the sign of the output response from positive to negative. The mild and short recession observed is the consequence of the countercyclical and strong reaction of the central bank to the external finance premium. As the beneficial financial shock reduces the external finance premium, the central bank sets a higher nominal interest rate which has a negative impact on aggregate demand through lower consumption and investment spending. In the model with unit banking elasticity (baseline), the central bank does not react actively to changes in the countercyclical external finance premium and the financial shock results in some economic expansion due to lower borrowing costs that stimulate demand and reduce the marginal costs of production.

The welfare effects of financial shocks are also amplified by banking rigidities. Both consumption and leisure report much larger reactions when banking rigidities are high (see Figure 3). In Table 4, we report that the welfare level is around 25 times higher than when the optimal monetary policy is conducted with unit banking elasticity. The welfare effects under different banking technologies are even greater if a Taylor rule is implemented by the central bank (the difference is captured by a factor of more than 80). Such differences can be also noticed in the standard deviations of either consumption and leisure as direct determinants of household welfare.

The Taylor rule also shows a much poorer performance when banking rigidities are in place. The lack of a straight response to the exogenous change in the external finance premium leads to a strong activation of the financial accelerator mechanism. The interest rate of loans falls and the economy expands both on the demand side (higher consumption and investment spending) and on the supply side (lower real marginal cost). The fall of the interest rate of loans is much deeper with banking rigidities $(-3.6 \%$ annualized versus $-0.4 \%$ annualized in the baseline model), which is transmitted to severe differences observed in the aggregate demand of the goods market and the rate of unemployment of the labor market.

\section{Conclusions}

This paper describes a dynamic model where both firms and households must borrow from banks to cover their expenditure plans. Banks provide financial services combining collateral and monitoring labor to produce loans. The introduction of external finance makes the cost of borrowing be one additional component of the structural equations for consumption, the stock of capital, the labor supply and the marginal cost of production. In the banking sector, the interest rate of loans is obtained as the sum of the interest rate of deposits plus the marginal cost of loan production. The use of firm equity as collateral in the production of loans brings a financial accelerator mechanism for the propagation of business cycle fluctuations.

We have calibrated the model for policy simulations under alternative settings of the loan production technology and different sources of shocks. In the baseline calibration based on US data during the Great Moderation period, there is a unit elasticity of substitution between collateral and labor in loan production, 
and technology, inflation and financial shocks simultaneously generate business cycle fluctuations.

The optimal monetary policy has been derived as a social planner's program that maximizes household welfare. Since consumption and leisure are the arguments of the utility function, the second-order approximation to intertemporal utility implies that the optimal rule should be targeting the volatilities of both consumption and leisure. In addition, we have designed an optimized instrument rule that provides simple responses of the interest rate to observable variables such as the rate of inflation, the rate of unemployment and the external finance premium, in a way fully implementable by modern central banks. These response coefficients have been estimated by making multiple simulations of the optimal policy constrained to the setting of the instrument rule. For testing conventional monetary policy, a Taylor rule has also been examined. The optimal rule leads the economy towards a flexible-price scenario: the real effects of technology shocks are amplified whereas the inflation shocks are basically neutralized with no significant real effects for output, consumption and unemployment. This opens a trade-off between stabilizing the goods market (Taylor rule) and the labor market (optimal rule), but it does not require any central-bank significant reaction to changes in the external finance premium. The optimized reactions of the nominal interest rate are quantitatively moderate to inflation deviations (0.59) and to the rate of unemployment (-0.10). In terms of policy performance, the optimized instrument rule provides a good approximation to the targeting rule and improves substantially the stabilizing capacity of the Taylor rule (the level of social welfare with the optimized rule almost improves by $50 \%$ the one obtained with the Taylor rule). Most of the welfare loss is explained by the effects of the inflation shock, which results in an economic recession under the Taylor rule that could have been neutralized by implementing the optimal policy.

With a low banking elasticity (0.1), the level of welfare drops by nearly $37 \%$ under the optimal rule, justified by a higher volatility of leisure time caused by banking rigidities and the financial accelerator. The optimized instrument rule requires reactions of negative sign to changes in the external finance premium (0.16) that were not required with a unit banking elasticity. The welfare loss of implementing a conventional Taylor rule is also significantly larger than in the baseline case.

Finally, when financial shocks drive the business cycles, the conventional Taylor rule would perform significantly worse than the optimal rule with higher variability in the labor market. The optimal policy in a financial business cycle requires stronger response coefficients of the nominal interest rate to changes in inflation (1.57), unemployment (-0.34) and the external finance premium (-0.26). The worst case for the stabilizing performance of a Taylor rule is a financial business cycle with banking rigidities, because the volatilities of consumption and leisure soar while social welfare plummets.

\section{References}

Altonji, J.A. (1986). Intertemporal substitution in labor supply: evidence from micro data, Journal of Political Economy 94, S176-S215. 
Angeloni, I., and E. Faia (2013). Capital regulation and monetary policy with fragile banks, Journal of Monetary Economics 60, 311-324.

Bernanke, B.S., and M. Gertler (1989). Agency Costs, Net Worth, and Business Fluctuations, American Economic Review, 79, 14-31.

Bernanke, B.S., M. Gertler. and S. Gilchrist (1999). The financial accelerator in a quantitative business cycle framework, in J.B. Taylor and M. Woodford (eds.) Handbook of Macroeconomics, Volume 1, Part 3, 1341-93. Elsevier.

Brunnermeier, M. K., Eisenbach, T. M., and Y. Sannikov (2012). Macroeconomics with Financial Frictions: A Survey, NBER Working Papers, \#18102.

Brunnermeier, M. K., and Y. Sannikov (2014). A Macroeconomic Model with a Financial Sector, American Economic Review 104, 379-421.

Calvo, G.A. (1983). Staggered pricing in a utility-maximizing framework, Journal of Monetary Economics 12, 383-396.

Carlstrom, C. T., and T. S. Fuerst (1997). Agency Costs, Net Worth, and Business Fluctuations: A Computable General Equilibrium Analysis, American Economic Review 87, 893-910.

Carlstrom, C.T., T.S. Fuerst, A. Ortiz, and M. Paustian (2014). Estimating contract indexation in a financial accelerator model, Journal of Economic Dynamics and Control 46, 130-149.

Casares, M. (2007). Firm-specific or Household-specific Sticky Wages in the New Keynesian Model?, International Journal of Central Banking 3, 181-240.

Casares, M., A. Moreno, and J. Vázquez (2014). An estimated New-Keynesian model with unemployment as excess supply of labor, Journal of Macroeconomics 40, 338-359.

Christiano, L, R. Motto and M. Rostagno (2008). Shocks, structures or monetary policies? The Euro Area and US after 2001, Journal of Economic Dynamics and Control 32, 2476-2506.

Christiano, L, R. Motto and M. Rostagno (2014). Risk Shocks, American Economic Review 104, 27-65.

Cúrdia, V., and M. Woodford (2010). Credit Spreads and Monetary Policy, Journal of Money, Credit, and Banking 42, Issue S1, 3-35.

Dixit, A.K., and J.E. Stiglitz (1977). Monopolistic competition and optimum product diversity, American Economic Review 67, 297-308.

Domeij, D., and M. Flodén (2006). The labor-supply elasticity and borrowing constraints: why estimates are biased, Review of Economic Dynamics 9, 242-262.

Faia, E., and T. Monacelli (2007). Optimal interest rate rules, asset prices, and credit frictions, Journal of Economic Dynamics and Control 31, 3228-3254.

Gertler, M., and P. Karadi (2011). A model of unconventional monetary policy, Journal of Monetary Economics 58, 17-34.

Giannoni, M. and M. Woodford (2005). Optimal Inflation Targeting Rules. In: Bernanke, Ben S., and Michael Woodford (eds.), The Inflation-Targeting Debate, University of Chicago Press, 93-162. 
Goodfriend, M. and B. T. McCallum (2007). Banking and interest rates in monetary policy analysis: A quantitative exploration, Journal of Monetary Economics 54, 1480-1507.

Gopinath, G. and O. Itskhoki (2010). In Search of Real Rigidities, in D. Acemoglu and M. Woodford (eds.), NBER Macroeconomics Annual, vol. 25, 261-309.

Kiyotaki, N., and J. Moore (1997). Credit Cycles, Journal of Political Economy 105, 211-248.

Levin, A. T., and J. C. Williams (2003). Robust Monetary Policy with Competing Reference Models. Journal of Monetary Economics 50, 945-975.

McCallum, B. T. (1988). Robustness Properties of a Rule for Monetary Policy. Carnegie-Rochester Conference Series on Public Policy 29, 173-203.

Pencavel, J.H., (1986). Labor supply of men: a survey. In: Ashenfelter, O., Layard, R. (Eds.), Handbook of Labor Economics. North-Holland, Amsterdam, 3-102.

Petrosky-Nadeau, N., and E. Wasmer (2011). Macroeconomic Dynamics in a Model of Goods, Labor and Credit Market Frictions, unpublished manuscript.

Ramsey, F. P. (1927). A contribution to the Theory of Taxation, Economic Journal 37, 47-61.

Smets, F. R., and R. Wouters (2003). An Estimated Dynamic Stochastic General Equilibrium Model of the Euro Area, Journal of the European Economic Association 1, 1123-1175.

Smets, F. R., and R. Wouters (2007). Shocks and Frictions in US Business Cycles: A Bayesian DSGE Approach, American Economic Review 97, 586-606.

Svensson, L. E.O., and M. Woodford (2005). Implementing Optimal Policy through Inflation-Forecast Targeting. In: Bernanke, Ben S., and Michael Woodford (eds.), The Inflation-Targeting Debate, University of Chicago Press, 19-83.

Taylor, J.B. (1993). Discretion versus policy rules in practice, Carnegie-Rochester Conference Series on Public Policy 39, 195-214.

Taylor, J. B. (1999a). Staggered Price and Wage Setting in Macroeconomics. In: Taylor, J. B., Woodford, M. (Eds.), Handbook of Macroeconomics. Elsevier, Amsterdam, vol 1B, pp. 1009-1050.

Taylor, J. B. (1999b). The Robustness and Efficiency of Monetary Policy Rules as Guidelines for Interest Rate Setting by the European Central Bank", Journal of Monetary Economics 43, 655-80.

Townsend, R. M. 1979. Optimal Contracts and Competitive Markets with Costly State Verification, Journal of Economic Theory 21, 265-293.

Villa, S (2016). Financial Frictions in the Euro Area and the United States: a Bayesian Assesment, Macroeconomic Dynamics 20, 1313-1340.

Walsh, C. E. (2010). Monetary Theory and Policy, 3rd ed., MIT Press.

Wasmer, E. and P. Weil, (2004). The Macroeconomics of Labor and Credit Market Imperfections. American Economic Review 94, 944-963.

Woodford, M. (1999). Commentary: How Should Monetary Policy Be Conducted in an Era of Price Stability? In: New Challenges for Monetary Policy: A Symposium Sponsored by the Federal Reserve Bank 
of Kansas City, Federal Reserve Bank of Kansas City.

Woodford, M. (2003). Interest and Prices: Foundations of a Theory of Monetary Policy. Princeton University Press. 


\section{Appendix}

\section{Household optimal consumption allocation}

For a given desired level of consumption bundles, $c_{t}$, the representative household chooses the amount of consumption of the differentiated good $\omega$ by solving the following maximization problem:

$$
\begin{aligned}
& \underset{c_{t}(\omega)}{\operatorname{Max}}\left[\int_{0}^{1} c_{t}(\omega)^{\frac{\theta_{p}-1}{\theta_{p}}} d \omega\right]^{\frac{\theta_{p}}{\theta_{p}-1}} \\
& \text { s.to }: c_{t}=\int_{0}^{1} \frac{P_{t}(\omega)}{P_{t}} c_{t}(\omega) d \omega
\end{aligned}
$$

where the aggregate price level is obtained from the Dixit-Stiglitz aggregation scheme

$$
P_{t}=\left[\int_{0}^{1} P_{t}(\omega)^{1+\theta_{p}} d \omega\right]^{\frac{1}{1+\theta_{p}}}
$$

First order conditions of this problem give the following demand curve ${ }^{21}$

$$
\frac{c_{t}(\omega)}{c_{t}}=\left(\frac{P_{t}(\omega)}{P_{t}}\right)^{-\theta_{p}}
$$

where $\theta_{p}>1$ is the Dixit-Stiglitz constant elasticity of substitution.

\section{Household optimal labor supply allocation.}

The aggregate labor supply to firms is a CES composite of heterogeneous labor services

$$
n_{t}^{s}=\left[\int_{0}^{1} n_{t}^{s}(\omega)^{\frac{1+\theta_{w}}{\theta_{w}}} d \omega\right]^{\frac{\theta_{w}}{1+\theta_{w}}}
$$

while the aggregate nominal wage is also obtained with a CES aggregation scheme

$$
W_{t}=\left[\int_{0}^{1} W_{t}(\omega)^{1+\theta_{w}} d \omega\right]^{\frac{1}{1+\theta_{w}}}
$$

The optimal allocation of labor supply across firms is determined by solving the problem

$$
\begin{aligned}
& \underset{n_{t}^{s}(\omega)}{\operatorname{Max}} \int_{0}^{1} W_{t}(\omega) n_{t}^{s}(\omega) d \omega \\
& \text { s.to }: n_{t}^{s}=\left[\int_{0}^{1} n_{t}^{s}(\omega)^{\frac{1+\theta_{w}}{\theta_{w}}} d \omega\right]^{\frac{\theta_{w}}{1+\theta_{w}}}
\end{aligned}
$$

The first order condition yields

$$
W_{t}(\omega)-\varkappa_{t}\left(n_{t}^{s}\right)^{-\frac{1}{\theta_{w}}} n_{t}^{s}(\omega)^{\frac{1}{\theta_{w}}}=0
$$

where $\varkappa_{t}$ is the Lagrangian multiplier. The optimal relative labor supply becomes

$$
\frac{n_{t}^{s}(\omega)}{n_{t}^{s}}=\left(\frac{W_{t}(\omega)}{\varkappa_{t}}\right)^{\theta_{w}}
$$

\footnotetext{
${ }^{21}$ Proof available in Walsh (2010), pages 331-332.
} 
As a standard result in monopolistically competitive markets, the Lagrange multiplier $\varkappa_{t}$ coincides with the aggregate price index. In this case, the price index is the nominal wage. Inserting $n_{t}^{s}(\omega)=\left(\frac{W_{t}(\omega)}{\varkappa_{t}}\right)^{\theta_{w}} n_{t}^{s}$ in the CES labor supply bundle gives

$$
n_{t}^{s}=\left[\int_{0}^{1}\left(\left(\frac{W_{t}(\omega)}{\varkappa_{t}}\right)^{\theta_{w}} n_{t}^{s}\right)^{\frac{1+\theta_{w}}{\theta_{w}}} d \omega\right]^{\frac{\theta_{w}}{1+\theta_{w}}}=\frac{n_{t}^{s}}{\varkappa_{t}^{\theta_{w}}}\left[\int_{0}^{1}\left(W_{t}(\omega)^{\theta_{w}}\right)^{\frac{1+\theta_{w}}{\theta_{w}}} d \omega\right]^{\frac{\theta_{w}}{1+\theta_{w}}}
$$

which can be solved for $\varkappa_{t}$ as follows

$$
\varkappa_{t}=\left[\int_{0}^{1} W_{t}(\omega)^{1+\theta_{w}} d \omega\right]^{\frac{1}{1+\theta_{w}}} \equiv W_{t}
$$

Replacing $\varkappa_{t}$ with $W_{t}$ in the optimal relative supply equation, it is obtained

$$
\frac{n_{t}^{s}(\omega)}{n_{t}^{s}}=\left(\frac{W_{t}(\omega)}{W_{t}}\right)^{\theta_{w}}
$$

\section{Log-linearized equation for aggregate firm earnings}

The real earnings and the real marginal cost for the representative $\omega$ firm are, respectively,

$$
e_{t}(\omega)=\frac{P_{t}(\omega)}{P_{t}} y_{t}(\omega)-\left(1+\tau_{f} r_{t}^{l}\right)\left(\frac{W_{t}(\omega)}{P_{t}} n_{t}(\omega)+r_{t}^{k} k_{t}(\omega)\right)
$$

and

$$
\xi_{t}(\omega)=\frac{\left(1+\tau_{f} r_{t}^{l}\right) \frac{W_{t}(\omega)}{P_{t}} n_{t}(\omega)}{(1-\alpha) y_{t}(\omega)}=\frac{\left(1+\tau_{f} r_{t}^{l}\right) r_{t}^{k} k_{t}(\omega)}{\alpha y_{t}(\omega)}
$$

Inserting the expressions for $\xi_{t}(\omega)$ into the earnings equation results in

$$
e_{t}(\omega)=\frac{P_{t}(\omega)}{P_{t}} y_{t}(\omega)-\xi_{t}(\omega)(1-\alpha) y_{t}(\omega)-\xi_{t}(\omega) \alpha y_{t}(\omega)=\frac{P_{t}(\omega)}{P_{t}} y_{t}(\omega)-\xi_{t}(\omega) y_{t}(\omega)
$$

Real earnings per output for firm $\omega$ yield

$$
\frac{e_{t}(\omega)}{y_{t}(\omega)}=\left(\frac{P_{t}(\omega)}{P_{t}}-\xi_{t}(\omega)\right)
$$

which in loglinear terms can be approximated as follows

$$
\widehat{e}_{t}(\omega)-\widehat{y}_{t}(\omega)=\frac{\mu}{\mu-1}\left(\widehat{P}_{t}(\omega)-\widehat{P}_{t}\right)-\frac{1}{\mu-1} \widehat{\xi}_{t}(\omega)
$$

where $\mu=\frac{\theta_{p}\left(1+\frac{1-\alpha}{\alpha+\theta_{w}}\right)}{\theta_{p}-1}$ is the steady-state mark-up. The aggregation across all firms $\widehat{e}_{t}=\int_{0}^{1} \widehat{e}_{t}(\omega) d \omega$ leads to

$$
\widehat{e}_{t}=-\frac{1}{\mu-1} \widehat{\xi}_{t}+\widehat{y}_{t}
$$

\section{Definition of equilibrium}

Given the stochastic shocks for technology, price indexation, and collateral in loan production, a recursive imperfectly competitive equilibrium is a sequence of prices $\left\{r_{t}^{d}, r_{t}^{l}, \operatorname{cs} y_{t}, P_{t}(\omega), W_{t}(\omega)\right\}$, with $\omega \in[0,1]$, such that agents behave optimally and markets are in equilibrium. 
The goods market equilibrium requires the aggregate supply be equal to the aggregate demand $\frac{1}{P_{t}} \int_{0}^{1} P_{t}(\omega) y_{t}^{s}(\omega) d \omega=\left(1+\tau_{h} r_{t}^{l}\right)\left[\int_{0}^{1} c_{t}(\omega)^{\frac{\theta_{p}-1}{\theta_{p}}} d \omega\right]^{\frac{\theta_{p}}{\theta_{p}-1}}+\left(1+\tau_{h} r_{t}^{l}\right) I\left(\frac{k_{t+1}}{k_{t}}\right) k_{t}+\left(x_{t+1}-x_{t}\right) v_{t}+\left(d_{t+1}-d_{t}\right)$

In the banking sector, the amount of real loans is $l_{t}=d_{t} B\left[a\left(e^{\varepsilon_{t}^{l}} v_{t}\right)^{\chi}+(1-a) m_{t}^{\chi}\right]^{\frac{1}{\chi}}$, which must be equal to firms and households total demand for real loans, as given by

$$
d_{t} B\left[a\left(e^{\varepsilon_{t}^{l}} v_{t}\right)^{\chi}+(1-a) m_{t}^{\chi}\right]^{\frac{1}{\chi}}=\int_{0}^{1} l_{t}^{f}(\omega) d \omega+l_{t}^{h}
$$

where $l_{t}^{f}(\omega)=\tau_{f}\left(\frac{W_{t}(\omega)}{P_{t}} n_{t}(\omega)+r_{t}^{k} k_{t}(\omega)\right)$ and $l_{t}^{h}=\tau_{h}\left(c_{t}+I\left(\frac{k_{t+1}}{k_{t}}\right) k_{t}\right)$.

For equilibrium in the deposit market, the households' aggregate demand for real deposits should be equal to the banks' aggregate supply of real deposits. The real amount of loans in the bank's balance sheet is equal to the supply of real deposits (abstracting from bank reserves). In turn, the equilibrium condition becomes

$$
d_{t}=l_{t}
$$

In the equity market, demand and supply of shares must be equal, which entails

$$
x_{t+1}=1
$$

In the market for labor at firms, aggregate supply and demand are, respectively,

$$
n_{t}^{s}=\left[\int_{0}^{1} n_{t}^{s}(\omega)^{\frac{1+\theta_{w}}{\theta_{w}}} d \omega\right]^{\frac{\theta_{w}}{1+\theta_{w}}} \text { and } n_{t}=\int_{0}^{1} n_{t}(\omega) d \omega
$$

while the aggregate rate of equilibrium unemployment is

$$
u_{t}=1-\frac{n_{t}^{s}}{n_{t}}
$$

In the market for labor services at banks, the amount of labor supplied by households is equal to the amount of labor demanded by banks

$$
m_{t}^{s}=m_{t}
$$

Finally, the capital goods rental market is in equilibrium when the total supply of the households is equal to the total demand by the firms

$$
k_{t}=\int_{0}^{1} k_{t}(\omega) d \omega
$$


5. Set of steady-state relationships

$$
\begin{aligned}
r^{l} & =r^{d}+\frac{w m}{l} \frac{a v^{\chi}+(1-a) m^{\chi}}{(1-a) m^{\chi}} \\
c s y & =w \frac{a}{(1-a)}\left(\frac{m}{v}\right)^{1-\chi} \\
v & =\frac{e}{\rho-c s y} \\
r^{d} & =\rho \\
e & =(1-\xi) y \\
\xi & =\alpha^{-\alpha}(1-\alpha)^{-(1-\alpha)}\left(1+\tau_{f} r^{l}\right)(w)^{1-\alpha}\left(r^{k}\right)^{\alpha} \\
\xi & =\frac{\theta_{p}-1}{\theta_{p}\left(1+\frac{1-\alpha}{\alpha+\theta_{w}}\right)} \\
l & =d \\
l & =\tau_{h}(c+\delta k)+\tau_{f}\left(w n+r^{k} k\right) \\
l & =d B\left[a v^{\chi}+(1-a) m^{\chi}\right]^{\frac{1}{\chi}} \\
w & =\Psi(1-n-m)^{-\gamma} c^{\sigma}\left(1+\tau_{h} r^{l}\right) \\
y & =k^{\alpha} n^{1-\alpha} \\
k & =n\left(\frac{\xi \alpha}{\left(1+\tau_{f} r^{l}\right) r^{k}}\right)^{1 /(1-\alpha)} \\
r^{k} & =\rho+\delta \\
y & =\left(1+\tau_{h} r^{l}\right)(c+\delta k) \\
u & =0
\end{aligned}
$$

Sixteen non-linear equations may provide solutions for the sixteen endogenous variables: $y, c, n, k, v$, $e, w, u, l, d, r^{k}, r^{l}, r^{d}, c s y, \xi$ and $m$.

6. Set of log-linear dynamic equations with an interest-rate (instrument) monetary policy rule

Consumption equation

$$
\widehat{c}_{t}=E_{t} \widehat{c}_{t+1}-\frac{1}{\sigma}\left(r_{t}^{d}-\rho\right)-\frac{\tau_{h}}{\sigma}\left(r_{t}^{l}-E_{t} r_{t+1}^{l}\right)
$$

New Keynesian Phillips curve

$$
\pi_{t}-\pi=\beta E_{t}\left(\pi_{t+1}-\pi\right)+\frac{(1-\eta)(1-\beta \eta)}{\eta\left(1+\frac{\theta_{p}(1-\alpha)}{\alpha+\theta_{w}}\right)}\left(\widehat{\xi}_{t}-\frac{(1-\alpha)}{\alpha+\theta_{w}} u_{t}\right)+\left(1-\beta \rho_{p}\right) \varepsilon_{t}^{p}
$$

Rate of unemployment as excess supply of labor

$$
u_{t}=\widehat{n}_{t}^{s}-\widehat{n}_{t}
$$


Overall resources constraint (goods market-clearing condition)

$$
\widehat{y}_{t}=\frac{\left(1+\tau_{h} r^{l}\right) c}{y} \widehat{c}_{t}+\frac{\left(1+\tau_{h} r^{l}\right) \delta k}{y} \widehat{i}_{t}+\tau_{h}\left(r_{t}^{l}-r^{l}\right)
$$

Capital accumulation equation

$$
\widehat{k}_{t+1}=\frac{1}{1+\beta} \widehat{k}_{t}+\frac{\beta}{1+\beta} E_{t} \widehat{k}_{t+2}+\frac{1}{(1+\beta) \epsilon}\left(\left(E_{t} r_{t+1}^{k}-r^{k}\right)-\left(r_{t}^{d}-\rho\right)-\tau_{h}\left(r_{t}^{l}-E_{t} r_{t+1}^{l}\right)\right)
$$

Optimal allocation for capital and labor demand

$$
\frac{1}{r^{k}}\left(r_{t}^{k}-r^{k}\right)-\widehat{w}_{t}=\widehat{k}_{t}-\widehat{n}_{t}
$$

Real interest rate of loans

$$
r_{t}^{l}-r^{l}=\left(r_{t-1}^{d}-\rho\right)-E_{t-1}\left(\pi_{t}-\pi\right)+\left(r^{l}-\rho\right)\left(\widehat{w}_{t}^{m}-\widehat{l}_{t}-\Omega(\chi-1)\left(\widehat{m}_{t}-\widehat{v}_{t}-\varepsilon_{t}^{l}\right)\right)
$$

Total demand for real loans

$$
\widehat{l}_{t}=\frac{\tau_{f} w n}{l}\left(\widehat{w}_{t}+\widehat{n}_{t}\right)+\frac{\tau_{f} r^{k} k}{l}\left(\frac{1}{r^{k}}\left(r_{t}^{k}-r^{k}\right)+\widehat{k}_{t}\right)+\frac{\tau_{h} c}{l} \widehat{c}_{t}+\frac{\tau_{h} \delta k}{l} \widehat{i}_{t}
$$

Loan production technology in credit market equilibrium $\left(d_{t}=l_{t}\right)$

$$
0=\Omega \varepsilon_{t}^{l}+\Omega \widehat{v}_{t}+(1-\Omega) \widehat{m}_{t}
$$

Real wage dynamics

$$
\widehat{w}_{t}=\widehat{w}_{t-1}+\pi_{t}^{w}-\pi_{t}
$$

Wage inflation equation

$$
\pi_{t}^{w}-\pi^{w}=\beta E_{t}\left(\pi_{t+1}^{w}-\pi^{w}\right)-\frac{(1-\eta)(1-\beta \eta)}{\eta\left(\alpha+\theta_{w}+\theta_{p}(1-\alpha)\right)}\left(u_{t}+\theta_{p} \widehat{\xi}_{t}\right)
$$

Portfolio choice for equity investment

$$
\widehat{v}_{t}=\frac{1}{1+\rho} E_{t} \widehat{v}_{t+1}+\frac{1}{1+\rho} E_{t}\left(c s y_{t+1}-c s y\right)+\frac{\rho-c s y}{1+\rho} E_{t} \widehat{e}_{t+1}-\left(r_{t}^{d}-\rho\right)
$$

Aggregate firm earnings

$$
\widehat{e}_{t}=-\frac{\xi}{1-\xi} \widehat{\xi}_{t}+\widehat{y}_{t}
$$

Collateral service yield of equity from banks optimizing program

$$
\operatorname{cs} y_{t}-\operatorname{cs} y=\operatorname{csy}\left(\widehat{w}_{t}^{m}+(\chi-1)\left(\widehat{v}_{t}-\widehat{m}_{t}\right)+\chi \varepsilon_{t}^{l}\right)
$$

Leisure time

$$
\widehat{l e i s}_{t}=-\frac{n+m}{1-n-m} \widehat{e l}_{t}
$$

Real marginal cost

$$
\widehat{\xi}_{t}=\tau_{f} r_{t}^{l}+(1-\alpha) \widehat{w}_{t}+\frac{\alpha}{r^{k}}\left(r_{t}^{k}-r^{k}\right)-\varepsilon_{t}^{z}
$$


Total effective labor (at both firms and banks)

$$
\widehat{e l}_{t}=\frac{n}{n+m} \widehat{n}_{t}+\frac{m}{n+m} \widehat{m}_{t}
$$

Cobb Douglas production technology

$$
\widehat{y}_{t}=\varepsilon_{t}^{z}+\alpha \widehat{k}_{t}+(1-\alpha) \widehat{n}_{t}
$$

Investment

$$
\widehat{i}_{t}=\frac{1}{\delta} \widehat{k}_{t+1}-\frac{(1-\delta)}{\delta} \widehat{k}_{t}
$$

Labor supply curve

$$
\frac{n}{1-n-m} \widehat{n}_{t}^{s}+\frac{m}{1-n-m} \widehat{m}_{t}=\frac{1}{\gamma}\left(\widehat{w}_{t}-u_{t}-\sigma \widehat{c}_{t}-\tau_{h}\left(r_{t}^{l}-r^{l}\right)\right)
$$

Banking labor supply curve

$$
\frac{n}{1-n-m} \widehat{n}_{t}^{s}+\frac{m}{1-n-m} \widehat{m}_{t}=\frac{1}{\gamma}\left(\widehat{w}_{t}^{m}-\sigma \widehat{c}_{t}-\tau_{h}\left(r_{t}^{l}-r^{l}\right)\right)
$$

Fisher relation for deposits

$$
r_{t}^{d}=R_{t}-E_{t} \pi_{t+1}^{p}
$$

External finance premium

$$
e f p_{t}-e f p=\left(r_{t}^{l}-r^{l}\right)-\left(r_{t-1}^{d}-\rho\right)-\frac{(c s y)(v)}{l}\left(\widehat{v}_{t}+\frac{1}{c s y}\left(c s y_{t}-c s y\right)-\widehat{l}_{t}\right)
$$

Monetary policy rule

$$
R_{t}-R=\left[\mu_{\pi}\left(\pi_{t}-\pi\right)+\mu_{u} u_{t}+\mu_{e f p}\left(e f p_{t}-e f p\right)\right]+\varepsilon_{t}^{R}
$$

Endogenous variables (24): $\pi_{t}^{w}, \pi_{t}, r_{t}^{k}, r_{t}^{l}, r_{t}^{d}, R_{t}, c s y_{t}, \widehat{y}_{t}, \widehat{k}_{t+1}, \widehat{n}_{t}, \widehat{n}_{t}^{s}, u_{t}, \widehat{c}_{t}, \widehat{i}_{t}, \widehat{w}_{t}, \widehat{w}_{t}^{m}, \widehat{\xi}_{t}, \widehat{e}_{t}, \widehat{v}_{t}, \widehat{l}_{t}, \widehat{m}_{t}$, $\widehat{e l}_{t}, \widehat{l e i s}_{t}$ and $e f p_{t}$.

Exogenous variables (4): $\operatorname{AR}(1)$ processes determine the evolution of the technology shock, $\varepsilon_{t}^{z}$, the financial shock, $\varepsilon_{t}^{l}$, the monetary policy (interest-rate) shock, $\varepsilon_{t}^{R}$, and the price indexation (inflation) shock, $\varepsilon_{t}^{p}$.

\section{The central-bank Ramsey problem}

In order to have a simpler set of relations in the competitive equilibrium, let us introduce one additional variable: total effective labor, $e l_{t}=n_{t}+m_{t}$. The bank choose prices and quantities of the variables of the competitive equilibrium in order to maximize intertemporal household utility. The list of endogenous variables includes $\widehat{c}_{t}, R_{t}-R, \widehat{w}_{t}, r_{t}^{k}-r^{k}, u_{t}, r_{t}^{l}-r^{l}, \widehat{e l}_{t}, \widehat{k}_{t+1}, \widehat{m}_{t}, \pi_{t}, \pi_{t}^{w}, \widehat{v}_{t}, \widehat{e}_{t}, \widehat{l}_{t}, c s y_{t}-c s y$, and $\widehat{l e i s} t$. We have used the definition of $e l_{t}$ and equations (A16)-(A22) to insert in the rest of the system the following seven relations

$$
\widehat{\xi}_{t}=\tau_{f} r_{t}^{l}+(1-\alpha) \widehat{w}_{t}+\frac{\alpha}{r^{k}}\left(r_{t}^{k}-r^{k}\right)-\varepsilon_{t}^{z}
$$




$$
\begin{gathered}
\widehat{n}_{t}=\frac{n+m}{n} \widehat{e l}_{t}-\frac{m}{n} \widehat{m}_{t} \\
\widehat{y}_{t}=\varepsilon_{t}^{z}+\alpha \widehat{k}_{t}+(1-\alpha) \widehat{n}_{t} \\
\widehat{i}_{t}=\frac{1}{\delta} \widehat{k}_{t+1}-\frac{(1-\delta)}{\delta} \widehat{k}_{t} \\
\widehat{n}_{t}^{s}=\frac{1}{\gamma} \frac{1-n-m}{n}\left(\widehat{w}_{t}-u_{t}-\sigma \widehat{c}_{t}-\tau_{h}\left(r_{t}^{l}-r^{l}\right)\right)-\frac{m}{n} \widehat{m}_{t} \\
\widehat{w}_{t}^{m}=\widehat{w}_{t}-u_{t} \\
r_{t}^{d}=R_{t}-E_{t} \pi_{t+1}^{p}
\end{gathered}
$$

so that we can drop the seven equations (A16)-(A22) and the seven variables $\widehat{\xi}_{t}, \widehat{n}_{t}, \widehat{y}_{t}, \widehat{i}_{t}, \widehat{n}_{t}^{s}, \widehat{w}_{t}^{m}$, and $r_{t}^{d}$ from the set of endogenous variables. This allows us to have a competitive equilibrium characterized by the set of equations from (A1) to $(\mathrm{A} 15) .{ }^{22}$

As described in Woodford (2003), we take the second-order approximation to the instantaneous utility function specification to obtain

$$
\frac{c_{t}^{1-\sigma}}{1-\sigma}+\Psi \frac{\left(1-n_{t}^{s}-m_{t}^{s}\right)^{1-\gamma}}{1-\gamma} \simeq \frac{c^{1-\sigma}}{1-\sigma}+c^{1-\sigma}\left(\widehat{c}_{t}-\frac{(\sigma-1)}{2} \widehat{c}_{t}^{2}\right)+\Psi \frac{\text { leis }^{1-\gamma}}{1-\gamma}+\Psi l s^{1-\gamma}\left(\widehat{\text { leis }}_{t}-\frac{(\gamma-1)}{2} \widehat{\text { leis }}_{t}^{2}\right)
$$

which brings the intertemporal welfare function

$$
\mathcal{W}_{t}=E_{t} \sum_{j=0}^{\infty} \beta^{j}\left(c^{1-\sigma}\left(\widehat{c}_{t+j}-\frac{(\sigma-1)}{2} \widehat{c}_{t+j}^{2}\right)+\Psi l s^{1-\gamma}\left(\widehat{l e i s}_{t+j}-\frac{(\gamma-1)}{2} \widehat{l e i s}_{t+j}^{2}\right)\right)
$$

whereas the equations describing the dynamics of the model are those that belong to the simplified system (A1)-(A15) in period $t$ and in any other previous or future periods.

The optimal control solution consists of the following 16 first order conditions ${ }^{23}$

$$
\begin{gathered}
c^{1-\sigma}(1-\sigma) \widehat{c}_{t}-\widetilde{\lambda}_{1, t}+\beta^{-1} \widetilde{\lambda}_{1, t-1}-\frac{(1-n-m)}{n} \frac{\sigma}{\gamma} \widetilde{\lambda}_{3, t}-\frac{c\left(1+\tau_{h} r^{l}\right)}{y} \widetilde{\lambda}_{4, t}-\frac{c \tau_{h}}{l} \widetilde{\lambda}_{8, t}-\frac{c\left(1+\tau_{h} r^{l}\right)}{y} \widetilde{\lambda}_{13, t}=0 \\
-\frac{1}{\sigma} \widetilde{\lambda}_{1, t}+\frac{1}{(1+\beta) \epsilon} \widetilde{\lambda}_{5, t}+\beta E_{t} \widetilde{\lambda}_{7, t+1}+\widetilde{\lambda}_{12, t}=0 \\
-\phi_{\pi}(1-\alpha) \widetilde{\lambda}_{2, t}+\frac{1-n-m}{n} \frac{1}{\gamma} \widetilde{\lambda}_{3, t}-\widetilde{\lambda}_{6, t}+\left(r^{l}-r^{d}\right) \widetilde{\lambda}_{7, t}-\frac{\tau_{f} w n}{l} \widetilde{\lambda}_{8, t}+\widetilde{\lambda}_{10, t} \\
-\beta E_{t} \widetilde{\lambda}_{10, t+1}+\theta_{\pi \xi}(1-\alpha) \widetilde{\lambda}_{11, t}+\frac{\xi(1-\alpha)}{1-\xi} \widetilde{\lambda}_{13, t}-c s y \widetilde{\lambda}_{14, t}=0 \\
-\frac{\phi_{\pi} \alpha}{r^{k}} \widetilde{\lambda}_{2, t}-\frac{1}{\beta(1+\beta) \epsilon} \widetilde{\lambda}_{5, t-1}+\frac{1}{r^{k}} \widetilde{\lambda}_{6, t}-\frac{\tau_{f} k}{l} \widetilde{\lambda}_{8, t}+\frac{\theta_{\pi \xi} \alpha}{r^{k}} \widetilde{\lambda}_{11, t}+\frac{\xi \alpha}{(1-\xi) r^{k}} \widetilde{\lambda}_{13, t}=0 \\
-\frac{n+m}{n} \widetilde{\lambda}_{3, t}+\frac{(1-\alpha)(n+m)}{n} \widetilde{\lambda}_{4, t}-\frac{n+m}{n} \widetilde{\lambda}_{6, t}-\frac{\tau_{f} w(n+m)}{l} \widetilde{\lambda}_{8, t}-\frac{n+m}{1-n-m} \widetilde{\lambda}_{15, t}=0
\end{gathered}
$$

\footnotetext{
${ }^{22}$ Equation (A23) is the definition of the external finance premium, ef $p_{t}$, and equation (A24) is the instrument rule for adjustments in the nominal interest rate, $R_{t}$. They both are dropped for the computation of the Ramsey-type optimal monetary policy.

${ }^{23}$ These definitions were used for simplifying notation:

$\phi_{\pi}=\frac{(1-\eta)(1-\beta \eta)\left(\alpha+\theta_{w}\right)}{\eta\left(\alpha+\theta_{w}+\theta_{p}(1-\alpha)\right)}, \phi_{\pi u}=\frac{(1-\eta)(1-\beta \eta)\left(\alpha+\theta_{w}\right)}{\eta\left(\alpha+\theta_{w}+\theta_{p}(1-\alpha)\right)} \frac{(1-\alpha)}{\left(\alpha+\theta_{w}\right)}, \theta_{\pi}=\frac{(1-\eta)(1-\beta \eta)}{\eta\left(\alpha+\theta_{w}+\theta_{p}(1-\alpha)\right)}$, and $\theta_{\pi \xi}=\frac{(1-\eta)(1-\beta \eta)}{\eta\left(\alpha+\theta_{w}+\theta_{p}(1-\alpha)\right)} \theta_{p}$.

As assumed throughout the paper, variables with no time subscript refer to the steady-state value.
} 


$$
\begin{aligned}
& -\frac{\left(1+\tau_{h} r^{l}\right) i}{y \delta} \widetilde{\lambda}_{4, t}+\beta\left(\alpha+\frac{\left(1+\tau_{h} r^{l}\right) i(1-\delta)}{y \delta}\right) E_{t} \widetilde{\lambda}_{4, t+1}+\widetilde{\lambda}_{5, t}-\frac{\beta}{1+\beta} E_{t} \widetilde{\lambda}_{5, t+1}-\frac{1}{1+\beta} \widetilde{\lambda}_{5, t-1}+\beta E_{t} \widetilde{\lambda}_{6, t+1}-\frac{\tau_{h} i}{l \delta} \widetilde{\lambda}_{8, t} \\
& -\left(\frac{\tau_{f} r^{k} k}{l}-\frac{\tau_{h} i(1-\delta)}{l \delta}\right) \beta E_{t} \widetilde{\lambda}_{8, t+1}-\frac{\left(1+\tau_{h} r^{l}\right) i}{y \delta} \widetilde{\lambda}_{13, t}+\frac{\left(1+\tau_{h} r^{l}\right) i(1-\delta)}{y \delta} \beta E_{t} \widetilde{\lambda}_{13, t+1}=0 \quad\left(\widehat{k}_{t+1}\right) \\
& -\frac{(1-\alpha) m}{n} \widetilde{\lambda}_{4, t}+\frac{m}{n} \widetilde{\lambda}_{6, t}+\left(r^{l}-r^{d}\right)(1-\Omega \chi) \widetilde{\lambda}_{7, t}+\frac{\tau_{f} w m}{l} \widetilde{\lambda}_{8, t}-\frac{1-\Omega}{\Omega} \widetilde{\lambda}_{9, t}+\operatorname{csy}(\chi-1) \widetilde{\lambda}_{14, t}=0 \\
& -\left(r^{l}-r^{d}\right) \widetilde{\lambda}_{7, t}+\widetilde{\lambda}_{8, t}=0 \\
& -\widetilde{\lambda}_{10, t}+\widetilde{\lambda}_{11, t}-\widetilde{\lambda}_{11, t-1}=0 \\
& \left(r^{l}-r^{d}\right) \Omega \chi \widetilde{\lambda}_{7, t}-\widetilde{\lambda}_{9, t}+\widetilde{\lambda}_{12, t}-\widetilde{\lambda}_{12, t-1}-\operatorname{csy}(\chi-1) \widetilde{\lambda}_{14, t}=0 \\
& -\left(r^{d}-c s y\right) \widetilde{\lambda}_{12, t-1}+\widetilde{\lambda}_{13, t}=0 \\
& -\frac{1}{\beta \sigma} \widetilde{\lambda}_{1, t-1}+\widetilde{\lambda}_{2, t}-\widetilde{\lambda}_{2, t-1}-\frac{1}{\beta(1+\beta) \epsilon} \tilde{\lambda}_{5, t-1}-\widetilde{\lambda}_{7, t}+\widetilde{\lambda}_{10, t}-\frac{1}{\beta} \widetilde{\lambda}_{12, t-1}=0 \\
& -\widetilde{\lambda}_{12, t-1}+\widetilde{\lambda}_{14, t}=0 \\
& \text { Ileis }{ }^{1-\gamma}(1-\gamma) \widehat{l e i s}_{t}-\widetilde{\lambda}_{15, t}=0 \\
& \phi_{\pi u} \widetilde{\lambda}_{2, t}-\left(1+\frac{(1-m-n)}{n} \frac{1}{\gamma}\right) \widetilde{\lambda}_{3, t}-\left(r^{l}-r^{d}\right) \widetilde{\lambda}_{7, t}+\theta_{\pi} \widetilde{\lambda}_{11, t}+c s y \widetilde{\lambda}_{14, t}=0 \\
& -\frac{\tau_{h}}{\sigma} \widetilde{\lambda}_{1, t}+\frac{\tau_{h}}{\sigma \beta} \widetilde{\lambda}_{1, t-1}-\phi_{\pi} \tau_{f} \widetilde{\lambda}_{2, t}-\frac{(1-m-n)}{n} \frac{\tau_{h}}{\gamma} \widetilde{\lambda}_{3, t}-\tau_{h} \widetilde{\lambda}_{4, t}+\frac{\tau_{h}}{(1+\beta) \epsilon} \widetilde{\lambda}_{5, t} \\
& -\frac{\tau_{h}}{(1+\beta) \epsilon \beta} \tilde{\lambda}_{5, t-1}-\widetilde{\lambda}_{7, t}+\theta_{\pi \xi} \tau_{f} \widetilde{\lambda}_{11, t}+\left(\frac{\xi \tau_{f}}{1-\xi}-\tau_{h}\right) \widetilde{\lambda}_{13, t}=0 \quad\left(r_{t}^{l}-r^{l}\right)
\end{aligned}
$$

where $\widetilde{\lambda}_{i, t+j}=\lambda_{i, t+j}-\lambda_{i}$, is the difference between the Lagrange multiplier of the equation (A $i$ ) written for period $t+j$ and its corresponding value in the steady state. The targeting rule also includes the following 15 competitive equilibrium constraints (which are equivalent to the set from A1 to A15)

$$
\begin{aligned}
& -\widehat{c}_{t}+E_{t} \widehat{c}_{t+t}-\frac{1}{\sigma}\left(\left(R_{t}-R\right)-E_{t}\left(\pi_{t+1}-\pi\right)\right)-\frac{\tau_{h}}{\sigma}\left(r_{t}^{l}-E_{t} r_{t+1}^{l}\right)=0 \\
& \left(\pi_{t}-\pi\right)-\beta E_{t}\left(\pi_{t+1}-\pi\right)-\phi_{\pi} \widehat{\xi}_{t}+\phi_{\pi u} u_{t}-\left(1-\beta \rho_{p}\right) \varepsilon_{t}^{p}=0 \\
& \frac{(1-m-n)}{n} \frac{1}{\gamma}\left(\widehat{w}_{t}-\sigma \widehat{c}_{t}-\tau_{h}\left(r_{t}^{l}-r^{l}\right)\right)-\frac{n+m}{n} \widehat{e l}_{t}-\left(1+\frac{1-n-m}{n} \frac{1}{\gamma}\right) u_{t}=0 \\
& \varepsilon_{t}^{a}+\alpha \widehat{k}_{t}+(1-\alpha)\left(\frac{n+m}{n} \widehat{e l}_{t}-\frac{m}{n} \widehat{m}_{t}\right)-\frac{\left(1+\tau_{h} r^{l}\right)}{y}\left(c \widehat{c}_{t}+\frac{i}{\delta}\left(\widehat{k}_{t+1}-(1-\delta) k_{t}\right)\right)-\tau_{h}\left(r_{t}^{l}-r^{l}\right)=0 \\
& \widehat{k}_{t+1}+\frac{1}{1+\beta} \widehat{k}_{t}-\frac{\beta}{1+\beta} E_{t} \widehat{k}_{t+2}-\frac{1}{(1+\beta) \epsilon} E_{t}\left(r_{t+1}^{k}-r^{k}\right)-\left(R_{t}-R\right)+E_{t}\left(\pi_{t+1}-\pi\right)-\tau_{h}\left(r_{t}^{l}-E_{t} r_{t+1}^{l}\right)=0\left(\lambda_{5, t}\right) \\
& \frac{1}{r^{k}}\left(r_{t}^{k}-r^{k}\right)-\widehat{w}_{t}-\frac{n+m}{n} \widehat{e l}_{t}+\frac{m}{n} \widehat{m}_{t}+\widehat{k}_{t}=0 \\
& \left(R_{t-1}-R\right)-E_{t-1}\left(\pi_{t}-\pi\right)+\left(r^{l}-r^{d}\right)\left(\widehat{w}_{t}-u_{t}-\widehat{l}_{t}+\Omega \chi\left(\varepsilon_{t}^{l}+\widehat{v}_{t}\right)+(1-\Omega \chi) \widehat{m}_{t}\right)-\left(r_{t}^{l}-r^{l}\right)=0 \\
& \widehat{l}_{t}-\frac{\tau_{f} w n}{l}\left(\widehat{w}_{t}+\frac{n+m}{n} \widehat{e l}_{t}-\frac{m}{n} \widehat{m}_{t}\right)-\frac{\tau_{f} r^{k} k}{l}\left(\frac{1}{r^{k}}\left(r_{t}^{k}-r^{k}\right)+\widehat{k}_{t}\right)-\frac{\tau_{h}}{l}\left(c \widehat{c}_{t}-i \delta^{-1}\left(\widehat{k}_{t+1}-(1-\delta) \widehat{k}_{t}\right)\right)=0\left(\lambda_{8, t}\right) \\
& -\varepsilon_{t}^{l}-\frac{1-\Omega}{\Omega} \widehat{m}_{t}-\widehat{v}_{t}=0 \\
& \widehat{w}_{t}-\widehat{w}_{t-1}-\left(\pi_{t}^{w}-\pi^{w}\right)+\left(\pi_{t}-\pi\right)=0
\end{aligned}
$$




$$
\begin{gathered}
\left(\pi_{t}^{w}-\pi^{w}\right)-\beta E_{t}\left(\pi_{t+1}^{w}-\pi^{w}\right)+\theta_{\pi} u_{t}+\theta_{\pi \xi}\left((1-\alpha) \widehat{w}_{t}+\frac{\alpha}{r^{k}}\left(r_{t}^{k}-r^{k}\right)+\tau_{f}\left(r_{t}^{l}-r^{l}\right)-\varepsilon_{t}^{a}\right)=0 \\
\widehat{v}_{t}-\beta E_{t} \widehat{v}_{t+1}-\beta E_{t}\left(c s y_{t+1}-c s y\right)-\beta(\rho-c s y) E_{t} \widehat{e}_{t+1}+\left(R_{t}-R\right)-E_{t}\left(\pi_{t+1}-\pi\right)=0 \\
\widehat{e}_{t}+\frac{\xi}{1-\xi}\left(\tau_{f}\left(r_{t}^{l}-r^{l}\right)+(1-\alpha) \widehat{w}_{t}+\frac{\alpha}{r^{k}}\left(r_{t}^{k}-r^{k}\right)-\varepsilon_{t}^{a}\right) \\
-\frac{\left(1+\tau_{h} r^{l}\right)}{y}\left(c \widehat{c}_{t}-\frac{i}{\delta}\left(\widehat{k}_{t+1}-(1-\delta) \widehat{k}_{t}\right)-\tau_{h}\left(r_{t}^{l}-r^{l}\right)=0 \quad\left(\lambda_{13, t}\right)\right. \\
\left(c s y_{t}-c s y\right)-c s y\left(\widehat{w}_{t}-u_{t}+(\chi-1)\left(\widehat{v}_{t}-\widehat{m}_{t}\right)-\chi \varepsilon_{t}^{l}\right)=0 \\
-\widehat{l e i s}_{t}-\frac{n+m}{1-n-m} \widehat{e l}_{t}=0
\end{gathered}
$$

The targeting rule comprises a total of 31 equations which may determine solution paths for 31 endogenous variables (16 of them are the choice variables and the remaining 15 variables are the Lagrange multipliers). If the central bank decides to implement the monetary policy through adjustments in the nominal interest, the solution path on the nominal interest could be written responding to 5 predetermined variables $\left(\widetilde{\lambda}_{1, t-1}, \widetilde{\lambda}_{2, t-1}, \widetilde{\lambda}_{5, t-1}, \widetilde{\lambda}_{11, t-1}, \widetilde{\lambda}_{12, t-1}\right)$ and $3 \operatorname{shocks}\left(\varepsilon_{t}^{a}, \varepsilon_{t}^{l}, \varepsilon_{t}^{p}\right)$. 


\title{
Ultimi Contributi di Ricerca CRENoS
}

\author{
I Paper sono disponibili in: http://www.crenos.it
}

16/11 Manuela Pulina, Valentina Santoni, "An analysis on the Italian agricultural firms: effects of public subsidies"

16/10 Tiziana Medda, Vittorio Pelligra, Tommaso Reggiani, "Does Experience Affect Fairness, Reciprocity and Cooperation in Lab Experiments?"

16/09 Bianca Biagi, Maria Giovanna Brandano, Manuela Pulina, "The effect of tourism taxation: a synthetic control approach"

16/08 Edoardo Otranto, Massimo Mucciardi, "A Flexible Specification of Space-Time AutoRegressive Models"

16/07 Leonardo Becchetti, Vittorio Pelligra, Francesco Salustri, "Testing for Heterogeneity of Preferences in Randomized Experiments: A Satisfaction-Based Approach Applied to Multiplayer Prisoners' Dilemmas"

16/06 Anna Bottasso, Maurizio Conti, Giovanni Sulis, "Firm Dynamics and Employment Protection: Evidence from Sectoral Data"

16/05 Oliviero A. Carboni, Giuseppe Medda, "R\&D, Export, and Investment Decision"

16/04 Leonardo Becchetti, Germana Corrado, Vittorio Pelligra, Fiammetta Rossetti, "Happiness and Preferences in a Legality Social Dilemma Comparing the Direct and Indirect Approach"

16/03 Leonardo Becchetti, Vittorio Pelligra, Francesco Salustri, Alejandra Vásquez. "Gender differences in Socially Responsible Consumption. An Experimental Investigation"

16/02 Leonardo Becchetti, Vittorio Pelligra, Alejandra Vásquez, "Are Women Naturaliter More Cooperative? An Experimental Investigation of the Vote-with-theWallet Game"

16/01 Leonardo Becchetti, Vittorio Pelligra, Fiammetta Rossetti, "The Corporate Legality Game A Lab Experiment on The Impact of Policies, Frames and Information"

15/22 Fabio Cerina, Luisanna Cocco, Katiuscia Mannaro, Michele Marchesi, Francesco Pigliaru, "Insularity and the development of a local network: a simulation model applied to the Italian railway system"

15/21 Fabio Cerina, "Is insularity a locational disadvantage? Insights from the New Economic Geography"

15/20 Giorgio Garau, Giovanni Mandras, "Economy-wide rebound effects from an increase in efficiency in the use of energy: the Italian case"

15/19 Bianca Biagi, Maria Gabriela Ladu, Marta Meleddu, Vicente Royuela, "Tourism and quality of life: a capability approach"

15/18 Gianfranco Atreni, Francesco Chessa, Luca G. Deidda, Malika Hamadi, Stefano Usai, "Access to microcredit and borrowers' behavior: Evidence from Sardinia"

15/17 Guerino Ardizzi, Federico Crudu, Carmelo Petraglia, "The Impact of Electronic Payments on Bank Cost Efficiency: Nonparametric Evidence"

15/16 Raffaele Brancati, Emanuela Marrocu, Manuel Romagnoli, Stefano Usai, "Innovation activities and learning processes in the crisis. Evidence from Italian export in manufacturing and services" 
Finito di stampare nel mese di Dicembre 2016 Presso Centro Stampa dell'Università degli Studi di Cagliari Via Università 40 09125 Cagliari 
www.crenos.it

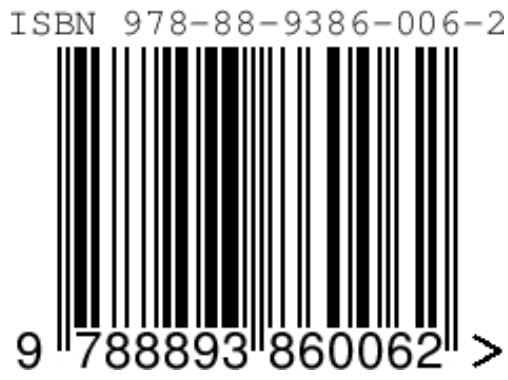

